WHOI $-72-45$

\title{
AN EXPERIMENTAL ANALYSIS OF THE DYNAMICS
}

OF A SUBMERGED TETHERED CRADLE

by

Jay Martin Cohen

WOODS HOLE OCEANOGRAPHIC INSTITUTION

Woods Hole, Massachusetts 02543

June 1972

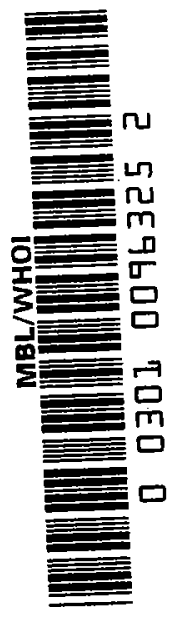

TECHNICAL REPORT

Prepared for the Office of Naval Research under Contract N00014-71-C-0107; NR 265-107.

Reproduction in whole or in part is permitted for any purpose of the United States Government. In citing this manuscript in a bibliogrophy, the reference should be followed by the phrase: UNPUBLISHED MANUSCRIPT.

Approved for public release, distribution uniimited.

Approved for Distribution

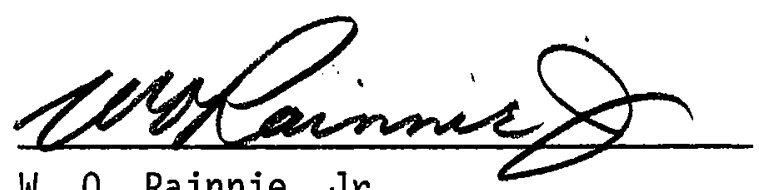

W. O. Rainnie, Jr.

Department of Ocean Engineering 
AN EXPERIMENTAL ANALYSIS OF THE DYNAMICS

OF A SUBMERGED TETHERED CRADLE

IN A SEAWAY

by

JAY MARTIN COHEN

Lieutenant, U.S. Navy

B.S., U.S. Nava1 Academy

(1968)

SUBMITTED IN PARTIAL FULFILLMENT OF - THE REQUIREMENTS FOR THE DEGREE OF

OCEAN ENGINEER

at the

MASSACHUSETTS INSTITUTE OF TECHNOLOGY

and the

WOODS HOLE OCEANOGRAPHIC INSTITUTION

and

MASTER OF SCIENCE IN NAVAL

ARCHITECTURE 'AND MARINE 'ENGINEERING

at the

MASSACHUSETTS INSTITUTE OF TECHNOLOGY

May, 1972

Signature of Author

Joint Program in Ocean Engineering, Massachusetts

Institute of Technology - Woods Hole

Oceanographic Institution, and Department of

Ocean Engineering, Massachusetts Institute of

Technology, May 1972

Certified by . . . . . . . . . . . . . . . . . . .

Thesis Supervisor

Certified by .............................

Thesis Supervisor

Accepted by. .............................

Chairman, Joint Committee for Ocean Engineering

Massachusetts Institute of Technology - Woods

Hole Oceanographic Institution 
ABSTRACT

Submerged recovery of small submersibles by means of surface tethered platforms offers the possibility of operations in sea states higher than is now possible using surface recovery means. The Woods Hole Oceanographic Institution's submersible support catamaran LULU has such a tethered system. The system consisting of cradle, chains, and hoist is designed to recover DSRV ALVIN at a depth of 100 feet, and then lift the submersible rapidly through the air-sea interface. Scientific commitments as well as possible damage to the cradle and/or ALVIN, and danger to personnel have prevented full scale recovery experiments. A $1 / 40$ scale model of the catamaran, chain and cradle was constructed to investigate cradle heave and pitch response in regular sinusoidal waves. Model tests were conducted at the Massachusetts Institute of Technology Tow Tank Facility and data was recorded electronically and photographically. Test runs were made at various ship speeds, cradle depths, wave heights, wave lengths, and cradle suspension modifications. Results indicate that for the existing system, cradle pitch and heave is only slightly attenuated over catamaran response at speeds less then 3 knots (full scale). By decreasing the number of cradle suspension points, and varying hoist resiliency and cradle added mass characteristics, cradle motion can be substantially reduced over catamaran motion. 


\section{ACKNOWLEDGEMENTS}

The advice and encouragement of many people contributed to this :study. In particular, I would like to thank the following perșons :

Claude Ronne for his invaluable photographic assistance; Jim Mavor and $J_{\circ} N$. Newman who were so helpful as thesis advisors; Wsabe 1 Mejia who helped so much with experiments at the M.I.T. Tow Tank; William Von Arx and David Owen who so kindly loaned me necessary photographic equipment; William 0 . Rainnie and a11 the members of the W.H.O.I. Deep Submergence Group; Allyn C. Vine for his direction and stimulation; Carl S. Albro and William Gallagher for assistance with mode1 construction; William Shultz and $J \circ R$. Sullivan for help with design and equipment fabrication; Kim Vandiver and members of M.I.T. course 13.36 for help with model tests; and a11 the members of Graphic Arts for their patience and excellent work.

Also I would like to thank my father and late mother for making this possible and my wife for her encouragement and patience. 
TABLE OF CONTENTS

Abstract

Acknow ledgements ii

List of Illustrations iv

List of Tables

vi

Notation vii

Int roducti on

Theory 11

Fabrication and Procedure 23

Results 33

Discussion of Results 42

Conclusions 43

Recommendations 45

Bibliog raphy 46

Appendix

A. Data used in model radius of gyration calculations

B. Data/graphical presentation 
$-i v-$

LIST OF ILLUSTRATIONS

1. DSRVT LULU underway with DSRV TURTLE

2. ALVIN maneuvering into surface recovery position

3. ALVIN in a state 4 sea

4. Summary of wind wave characteristics

5. Bow view of DSRVT LULU

6. LULU lift cradle and hoist for ALVIN recovery

7. Catamaran model theoretical and experimental response characteristics

8. Schematic catamaran-chain-cradle system

9. Single degree of freedom a) forced vibration amplitude, and b) phase angle between force and displacement

10. Comparison of Moskowitz family of sea spectra obtained by random sampling with family of ideal average spectra

11. $1 / 40$ scale model of DSRVT LULU and cradle (shown unpainted)

12. Recovery cradle

13. Model cradle suspended 30 inches beneath catamaran via fourpoint chain suspension

14. Data taking equipment

15. Overall equipment arrangement at M.I.T. Tow Tank

16. Representative sequence of cradle motion

17. Model cradle showing spring detail

18. Mode1 cradle alteration with two point spring suspension and flat plate

19. Catamaran response in the equivalent of 8.5 foot high, 120

foot long regular waves full scale

20. Plot of theoretical and actual model cradle heave response

B1. Catamaran heave response $\left(h_{0}=1^{\prime \prime}\right)$

B2. Catamaran heave response $\left(h_{0}=2.5^{\prime \prime}\right)$

B3. Cradle heave response $\left(\mathrm{h}_{0}=1^{\prime \prime}\right)$ 
B4. Cradle heave response $\left(h_{0}=2.5^{\prime \prime}\right)$

B5. Catamaran pitch response $\left(h_{0}=1^{\prime \prime}\right)$

B6. Catamaran pitch response $\left(h_{0}=2.5^{\prime \prime}\right)$

B7. Cradle pitch response $\left(h_{0}=1^{\prime \prime}\right)$

B8. Cradle pitch response $\left(h_{0}=2.5 "\right)$

B9. Modified cradle heave response

B10. Modified cradle pitch response 


$$
\begin{aligned}
& -v i- \\
& \text { LIST OF TABLES }
\end{aligned}
$$

I. Characteristics of Fully Arisen Sea

II. Full Scale and Model Characteristics

III. Summary of Horizontal Cradle Displacement and Cradle Surge Oscillation 
NOTATION

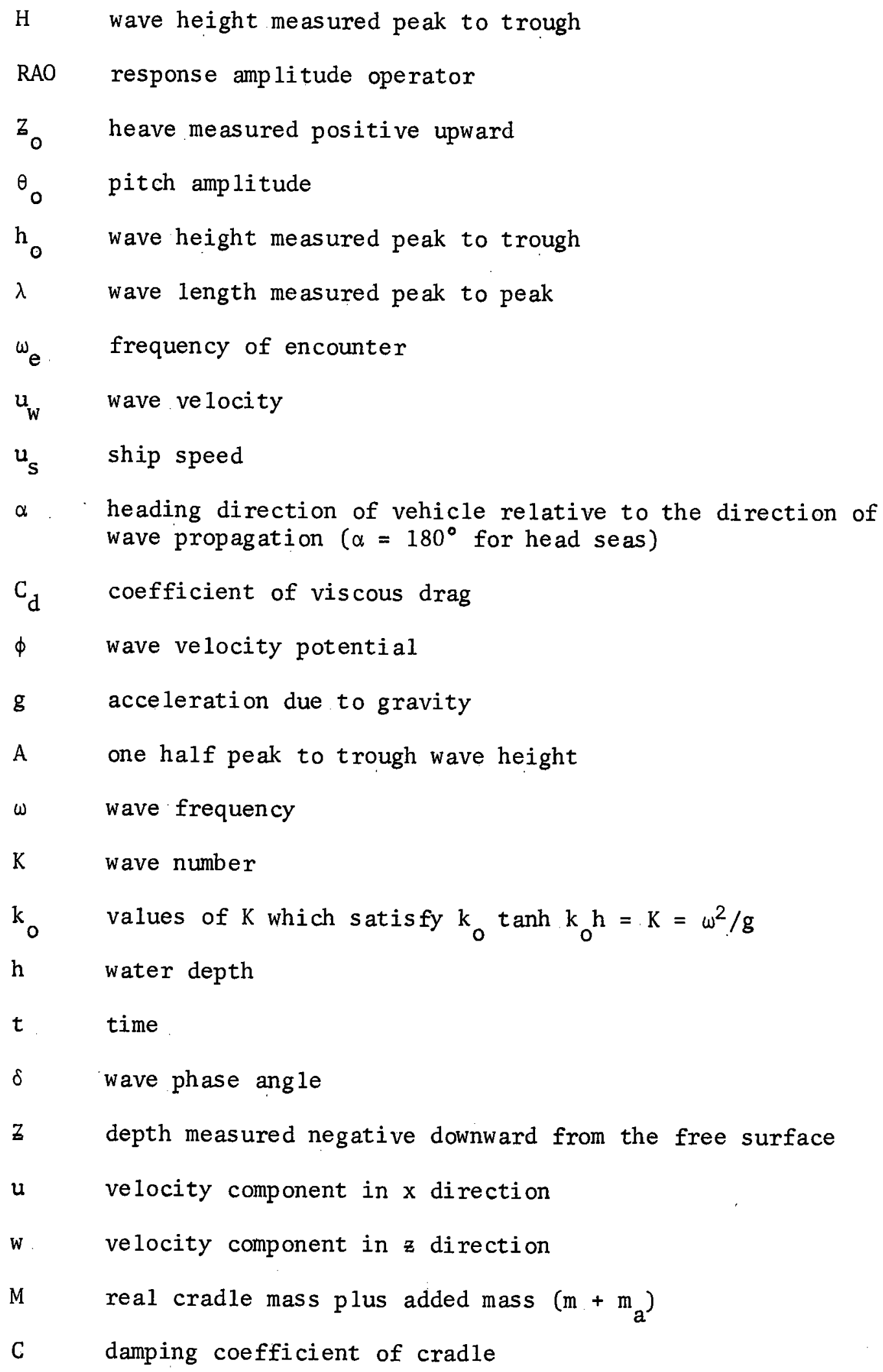


-viii-

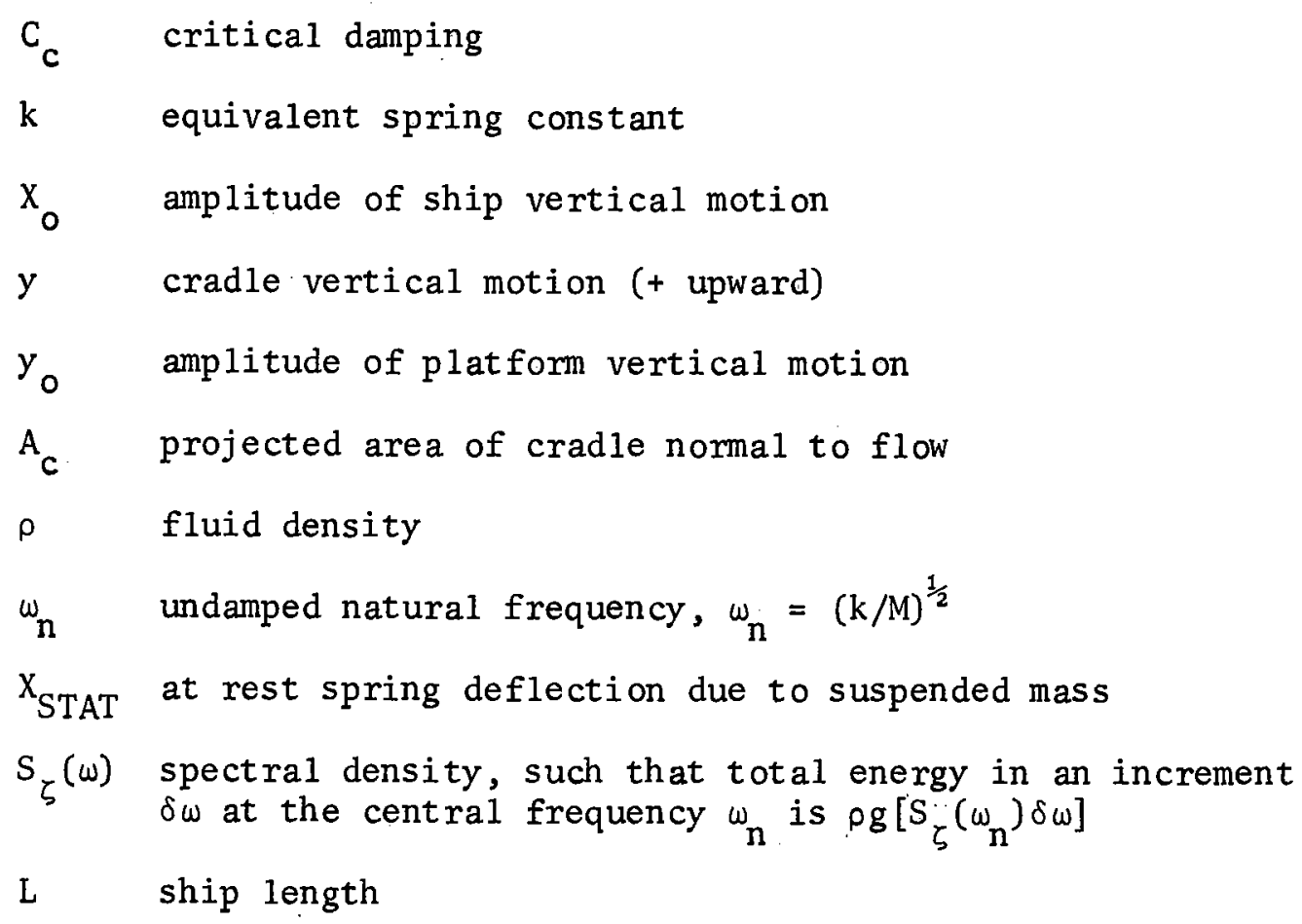


INTRODUCTION

The Deep Submergence Research Vehicle (DSRV) ALVIN and her support catamaran LULU are perhaps the most successful deep submersible combination that regularly operates in the open ocean. Funded and owned by the U.S. Navy and operated by the Woods Hole Oceanographic Institution, ALVIN has to date completed 390 dives in six operating seasons from 1964 to 1971. The most recent operating period, lasting from 4 June 1971 to 17 December 1971, was ALVIN's most active with a total of 82 dives.

As presently configured (Figure 1), LULU has a 30 ton net capacity cradle with four-point chain hoists located between her two hulls just aft of mid-ships. During transit, the cradle is two-blocked in the raised position such that the top of the cradle is flush with the surrounding deck, providing easy access for maintainence of ALVIN. Launch of the submersible is executed by having the catamaran lie to with the sea astern, while the cradle is lowered so that it is clear of the floating submersible. Snubber lines prevent lateral relative motion between ALVIN and LULU until the pilot on board ALVIN has powered her clear of LULU's stern at which time all lines are removed, and the dive can commence. Retrieval is the reverse of the launch sequence. Upon completion of the dive, ALVIN surfaces well clear of LULU. The two vessels then close each other with the aid of visual and/or radio direction devices. The catamaran maneuvers such that the seas are astern (Figure 2), at which time ALVIN approaches LULU, receives snubber lines, drives herself between the hulls, and is positioned over the submerged cradle. When alignment is correct, the cradle 


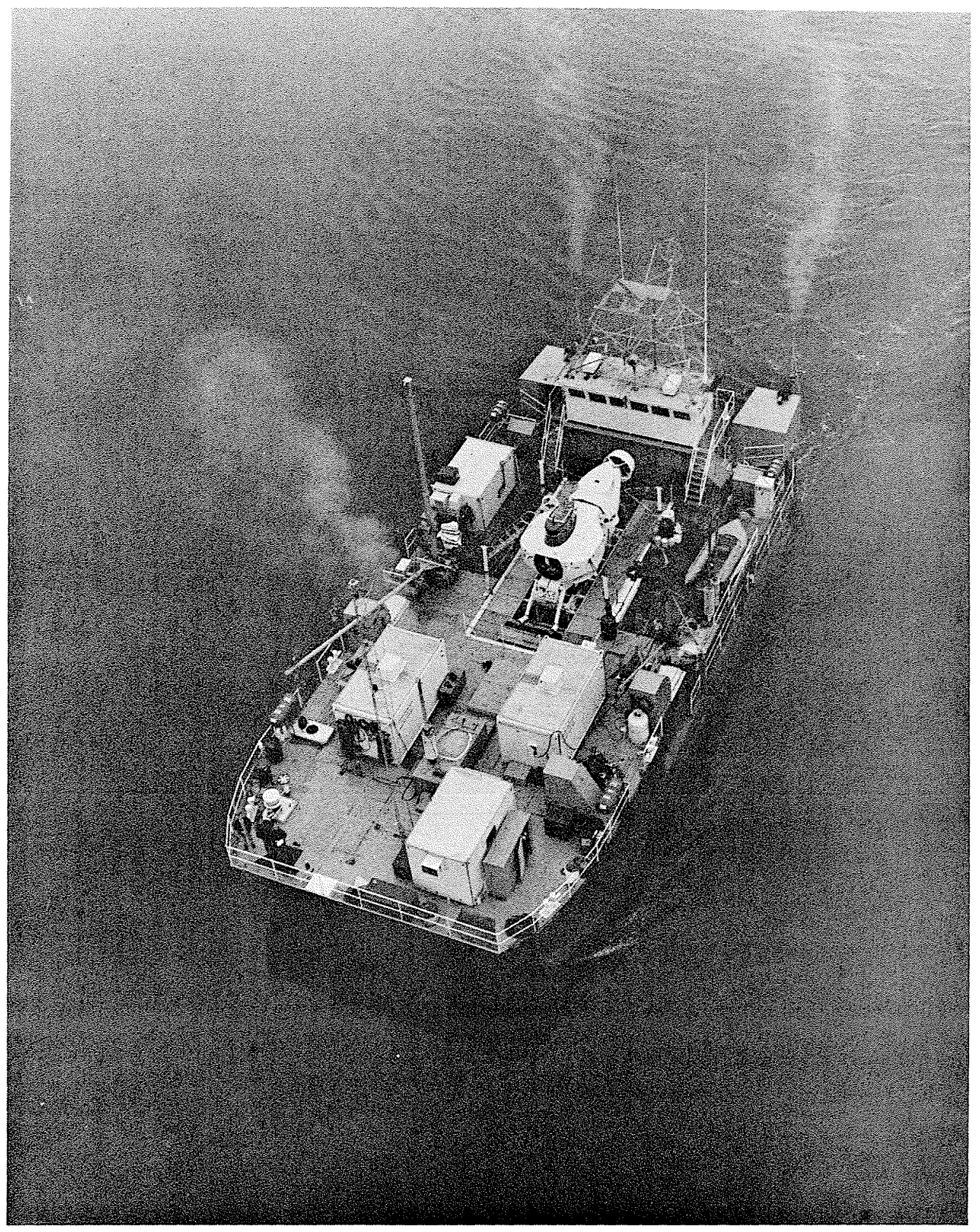

Figure 1. DSRVT LULU Underway with DSRV TURTLE. 

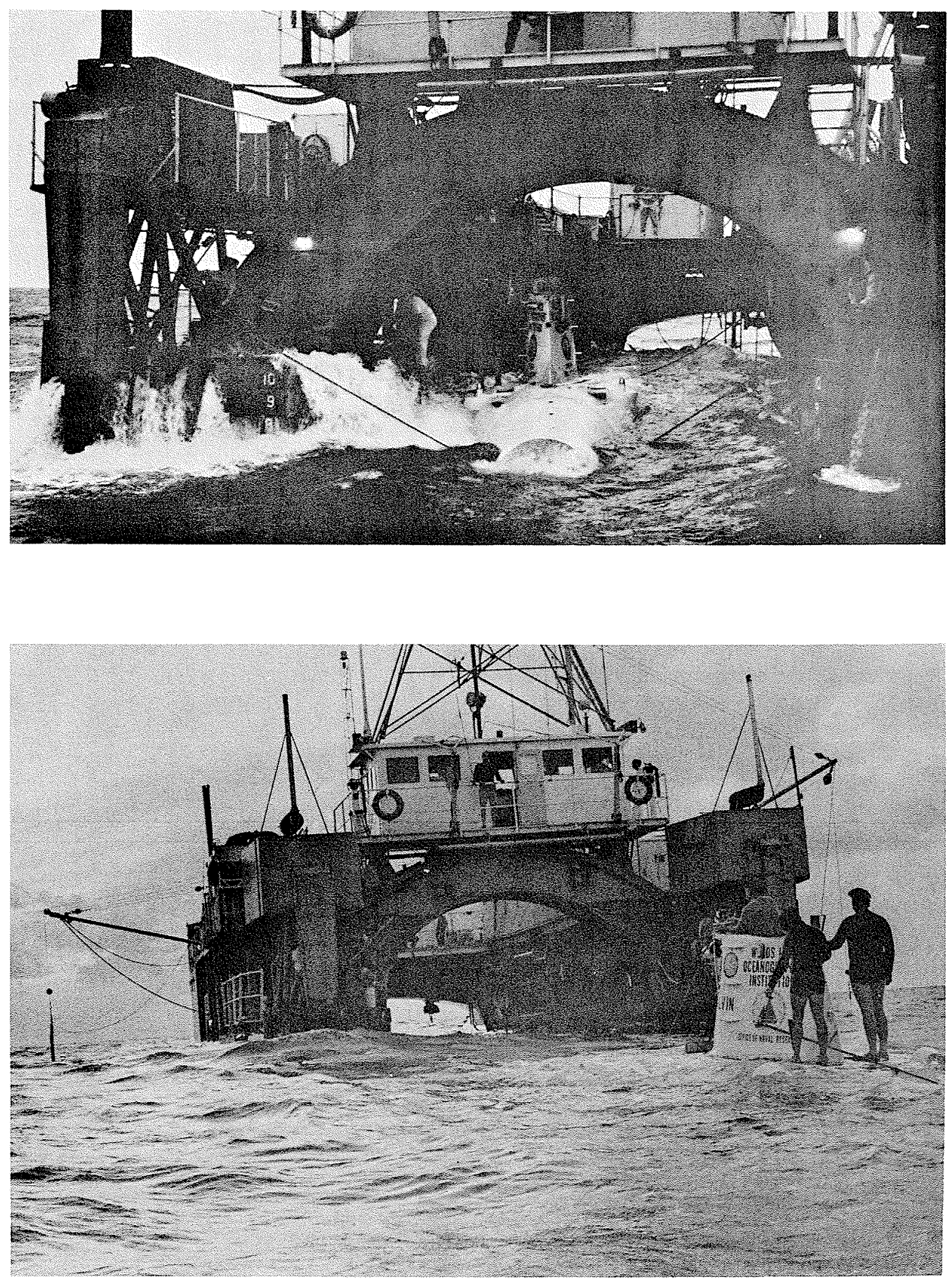

Figure 2. ALVIN Maneuvering into Surface Recovery Position. 
is raised with ALVIN aboard at a rate of 30 feet per minute, until the combination is we 11 clear of the air-sea interface, and secured to the catamaran's deck.

It is this unique combination of catamaran, cradle, and manned submersible, which has enabled launch and retrieval consistently up to sea state 3 , with rare instances of recovery in sea state 4 necessitated by unexpected weather changes during the period of a dive. The single greatest unscheduled factor in dive cancellations is weather. Of the 196 days of operation in 1971, 27 were lost due to unsatisfactory weather conditions. As Mavor (1971) states, depending upon ship location and forecast or actual weather on station, one of the following reasons for dive cancellation will result:

$$
\begin{aligned}
& \text { Weather Forecast: } \begin{array}{l}
\text { 1) hurricane/full gale - cancels or post- } \\
\text { pones cruise }
\end{array} \\
& \begin{array}{l}
\text { 2) sea state } 4 \text { - cancels dive on station } \\
\text { 3) gale - aborts cruise on station }
\end{array} \\
& \text { Weather on Station: 1) sea state } 4 \text { - aborts/postpones dive } \\
& \text { 2) large storm - may abort cruise } \\
& \text { 3) fog - aborts/postpones dive }
\end{aligned}
$$

In particular, Mavor cites a recurring cause for dive cancellation in the North At lantic off Cape Cod as an increase from sea state 3 to 4 on days when the prevailing southwest wind increases from 10 knots in the morning to 20 knots in the afternoon. Figure 3 is included to assist the reader in better understanding the magnitude of state 4 sea in relation to a 15 ton, 23 foot long vehicle. Table I and Figure 4 quantitatively define characteristics 


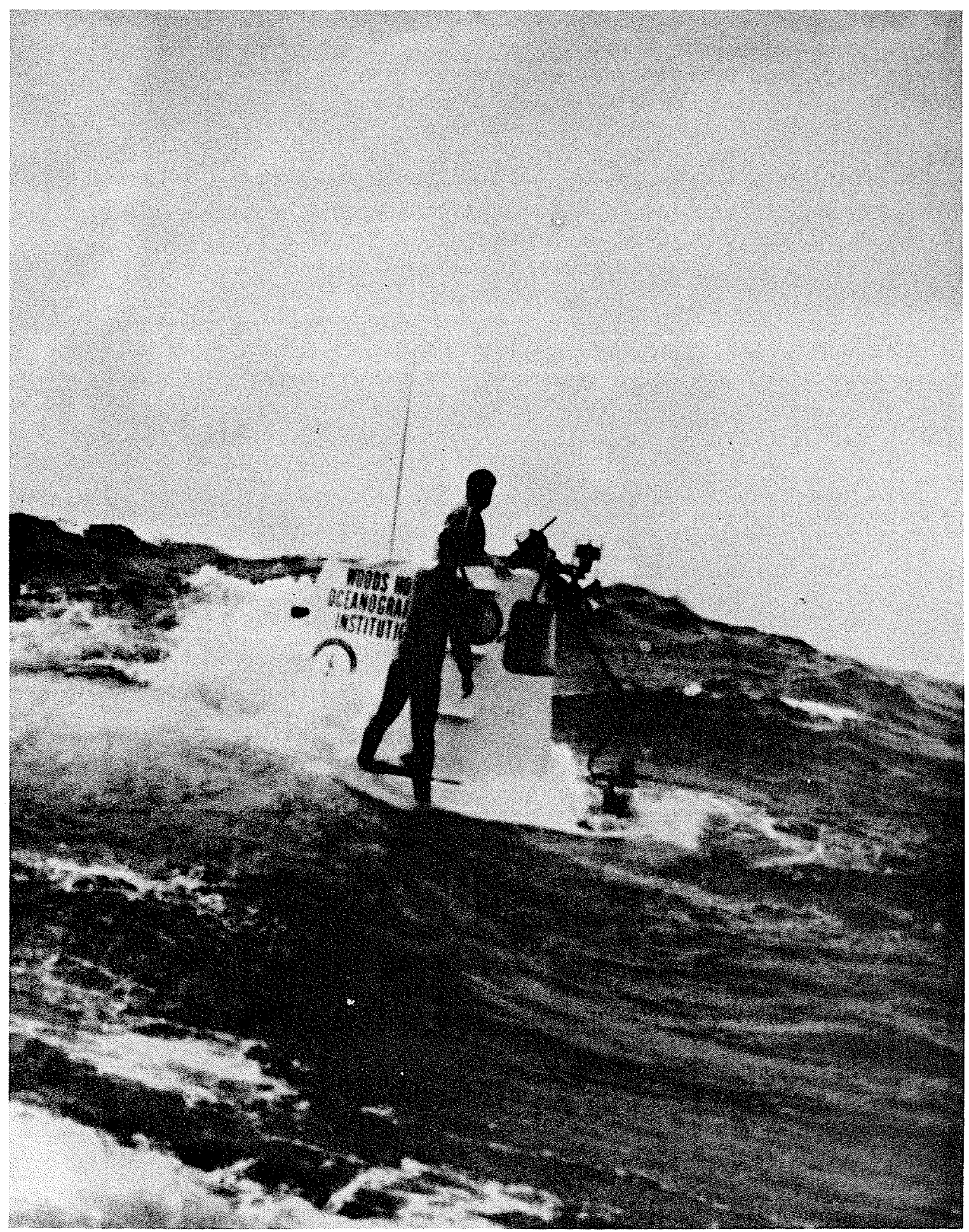

Figure 3. ALVIN in a State 4 Sea. 
$-6-$

Table I. Characteristics of Fully Arisen Sea.

(After W. Marks, Geo-Marine Technology Nov. 1964).

\begin{tabular}{|c|c|c|c|c|c|c|c|c|}
\hline Sea & State & $\begin{array}{l}\text { Wind } \\
\text { Vel. } \\
\text { (kts) }\end{array}$ & Mean & $\begin{array}{l}\text { Wave Heigh } \\
\quad(\mathrm{ft} . \text { ) } \\
\text { Sig. } \mathrm{H}^{1 / 3}\end{array}$ & $\mathrm{H}^{1 / 10}$ & Max. Energy & Mean & $\begin{array}{l}\text { Length } \\
(\mathrm{ft}) \\
\text { Average }\end{array}$ \\
\hline & 1 & $4-7$ & $.18-.6$ & $.29-1$ & $.37-1.2$ & $2-3.4$ & $1.4-2: 4$ & 6. 7-20 \\
\hline & 2 & $7-14$ & $.88-1.8$ & $1.4-2.9$ & $1.8-3.7$ & $4-5.4$ & $2.9-3.9$ & $27.0-52$ \\
\hline & 3 & $14-16$ & $2.0-2.9$ & $3.3-4.6$ & $4.2-5.8$ & $5.6-6.5$ & $4.0-4.6$ & $59.0-71$ \\
\hline & 4 & $17-20$ & $3.8-4.3$ & $6.1-6.9$ & $\begin{array}{lll}7.8 & -8.7\end{array}$ & $7.2-7.7$ & $5.1-5.4$ & $90.0-99$ \\
\hline & 5 & $20-23$ & $\begin{array}{lll}5.0 & -7.9\end{array}$ & $\begin{array}{lll}8.0 & -12\end{array}$ & $13.0-16$ & $8.1-9.7$ & $5.7-6.8$ & $111.0-160$ \\
\hline & 6 & $24-30$ & $8.2-11$ & $13.0-18$ & $17.0-23$ & $9.9-11.3$ & $7.0-7.9$ & $164.0-212$ \\
\hline
\end{tabular}

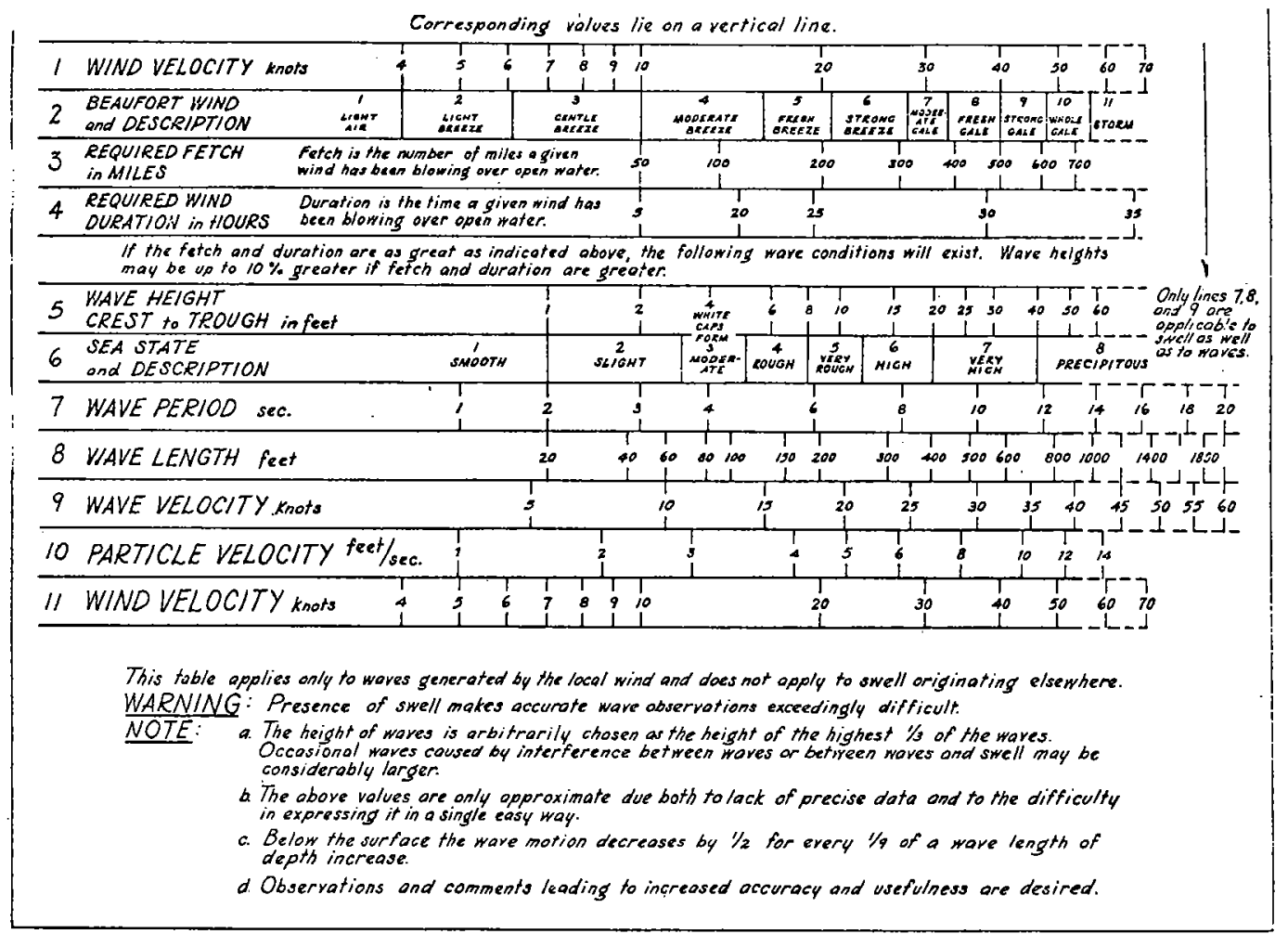

VINE s. VOLKATANN W.H.O.1. JUNE, 19S:

Figure 4. Summary of Wind Wave Characteristics. (Reproduced from Vine and Volkman 1950). 
of a fully arisen wind driven sea. Average sea state statistics for the North Atlantic according to Wiegel (1964), show that for the months of May, June, and July, sea states 1 thru 3 will occur 25 per cent of the time, while a sea state of 4 thru $41 / 2$ (wave height 5-10 feet) will occur 37 per cent of the time. For the months of August, September, and October, sea states 1 thru 3 have only a 7 per cent occurrence, while state 4 thru $41 / 2$ seas occur 36 per cent of the time. It is obvious then, that a capability to consistently recover ALVIN in state 4 seas would substantially decrease the number of dives cancelled due to weather. Since the consistent recovery of ALVIN in a state 4 sea by the means already described would be difficult at best, and certainly dangerous to equipment and personne1, an alternate approach to recovery is seriously being considered. In 1969, anticipating the arrival of DSRV SEA CLIFF, LULU was extensively modified. In addition to a new bow (Figure 5), increased deck space for crew and equipment, increased displacement via added double hulls on each pontoon, and a new cradle to handle the 25 ton submersible, a four point chain hoist system was installed. Four 120 feet long lengths of 6 inch chain links over four synchronized wildcats form the hoist system for the cradle (Figure 6). This capability to lower the cradle to a depth of $100 \mathrm{feet}$, where surface wave action is significantly attenuated, offers the possibility of submerged mating of ALVIN to the cradle in seas higher than sea state 3. Once docking is accomplished, a rapid transit through the air/sea interface would avoid dangerous relative motion between the catamaran and cradle. 

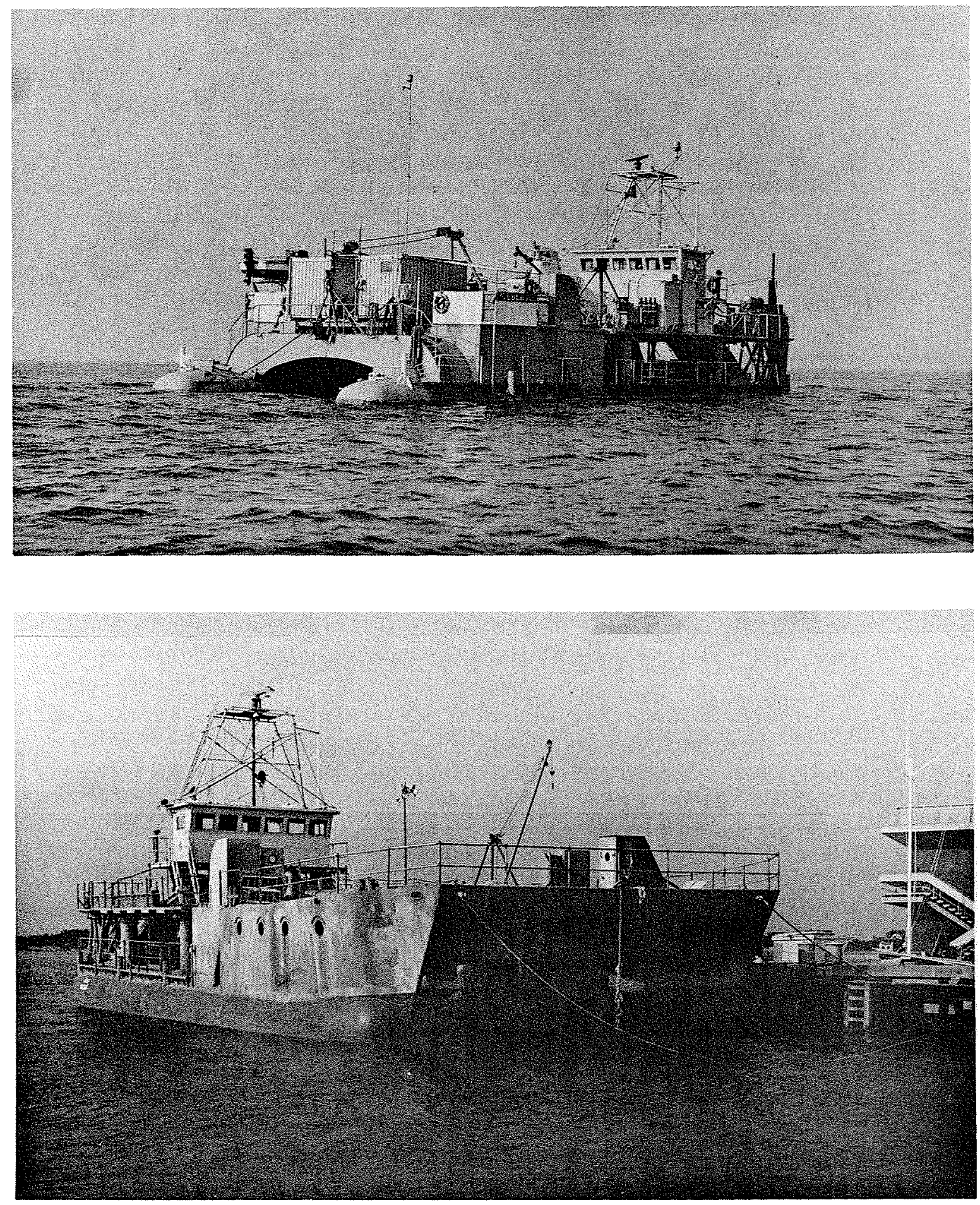

Figure 5. Bow View of DSRVT LULU a) Before

Alteration and, b) After Alteration. 

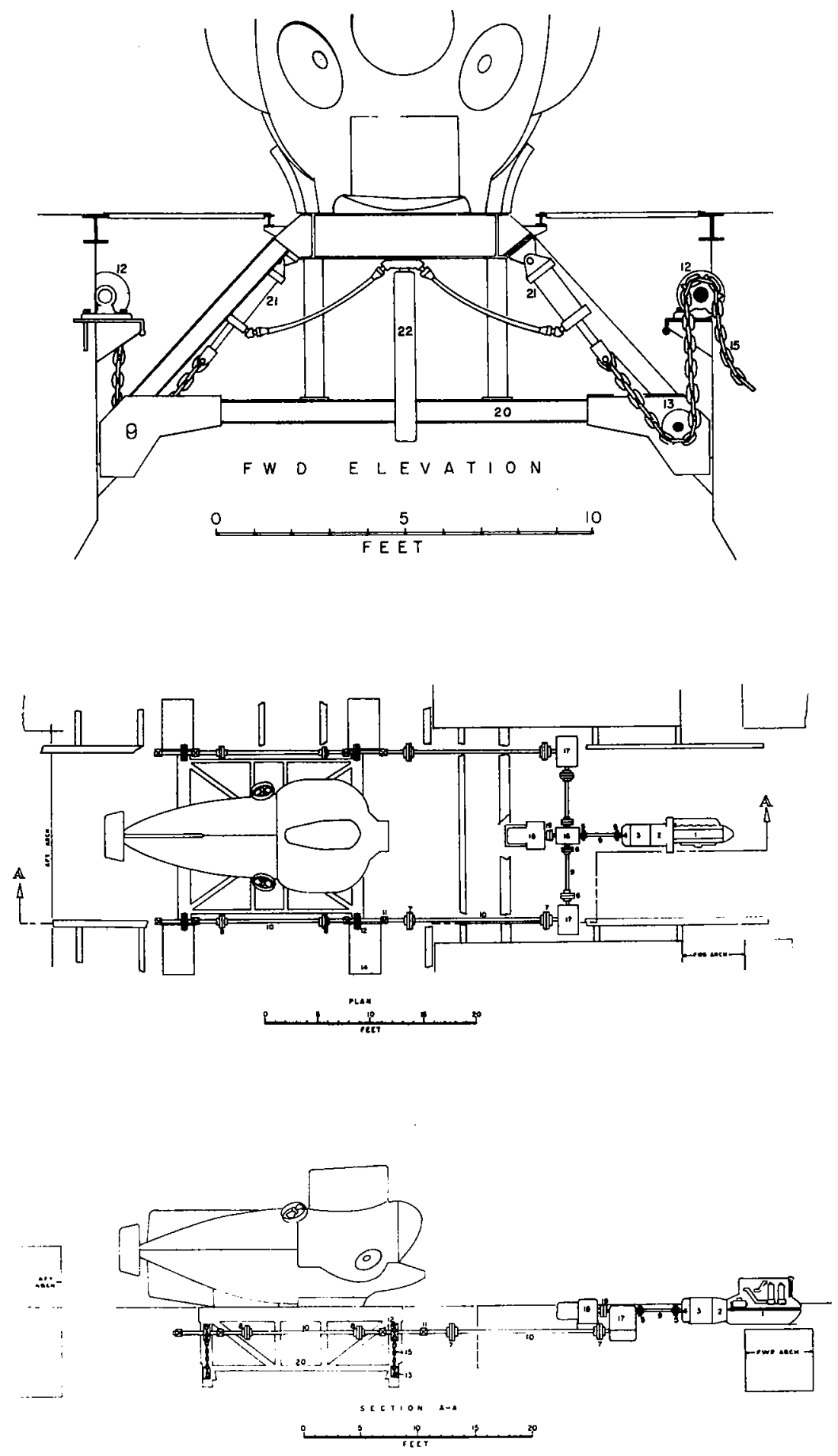

Figure 6. LULU Lift Cradle and Hoist for ALVIN Recovery a) Forward Elevation, b) Plan View, and c) Side Elevation. (Reproduced from Aldrich 1971). 
Full scale system testing without prior analysis and motion prediction would require elaborate instrumentation, valuable time diverted from scientific commitments, and possible damage to ALVIN, LULU, the cradle and danger to personnel. For this reason it was proposed that scale model tests be conducted before full scale trials and/or modification. The following then is a report of the preparation, execution, and results of mode 1 tests conducted using a $1 / 40$ scale model of LULU with her cradle suspended at a scale depth of 100 feet, over a range of ship speeds, wave heights, wave lengths, and system alterations. 
THEORY

Much study has been given to the dynamics of a submerged tethered cradle acted upon by ship motion and wave force. Vandiver (1969) and Heller and Motherway (1971) have extensively analyzed such systems in terms of discrete spring-mass-viscous damped configurations. Kenny (1969) repeated much of Vandiver's work, with additional effort directed toward a physical model to verify theoretical calculations. To my knowledge, the only similar experimental work was carried on by the Naval Ship Research and Development Center, where the new catamaran ASR and Deep Submergence Rescue Vehicle (DSRV) retrieval cradle and hoist were evaluated.

This thesis is primarily an experimental analys is which compliments the above studies. Theoretical analysis is limited to that necessary to justify assumptions made in modeling, validity of experimental data, and as a guide to the alterations necessary for acceptable performance of the cradle in state 4 seas.

The first area of interest is LULU's response amplitude operator (RAO), since the direct driving force producing cradle motion is the heave and pitch of the catamaran. The RAO is defined as the magnitude of response (measured from the calm water position) of heave $\left(z_{0}\right)$ and pitch $\left(\theta_{0}\right)$ over a series of wave lengths for a given ship speed non-dimensionalized by wave height $\left(h_{0}\right)$ and wave slope $\left(2 \pi h_{0} / \lambda\right)$ respectively. If the response of a ship is in fact linear, then for a given frequency of encounter $\left(\omega_{e}\right)$, where:

$$
\omega_{e}=\frac{2 \pi}{\lambda}\left(u_{w}-u_{s}^{\cdot} \cos \alpha\right)
$$




$$
\begin{aligned}
\lambda= & \text { wave length } \\
u_{w}= & \left(\frac{g \lambda}{2 \pi}\right)^{\frac{1}{2}}=\text { wave velocity } \\
u_{s}= & \text { ship speed } \\
\alpha= & \text { heading direction of vehicle relative } \\
& \text { to the direction of wave propagation } \\
& \left(\alpha=180^{\circ} \text { for head seas }\right)
\end{aligned}
$$

the ratio $z_{0} / h_{0}$ and $\theta_{0} /\left(2 \pi h_{0} / \lambda\right)$ will remain constant as wave height is varied.

Such response operators may be derived from model tests, or more recently, from computer programs using "strip theory" as described in Korvin-Kroukovsky (1961). Booth (1967) conducted mode 1 tests on $1 / 20 \mathrm{scale}$ models of LULU and ALVIN. The models were positioned in the surface recovery position, with ALVIN between the catamaran hulls at zero speed, encountering head seas of height. 1.25 and 2.5 feet (full scale). Response of these vehicles was also calculated using the M.I.T. ship motion computer program. The results of these two approaches for LULU are included (Figure 7). Tow tank tests on my $1 / 40$ scale mode 1 equivalent to Booth's showed excellent agreement in heave and pitch with the theoretical and experimental results displayed in Figure 7.

Froude scaling was applied to the cradle as well as the catamaran, since the coefficient of viscous drag $\left(C_{d}\right)$ is nearly independent of Reynolds number for sharp edged objects such as the plates and girders which make up the horizontal cross-section of the recovery cradle. The full scale recovery system consists of LULU, the cradle, and four 120 foot lengths of one inch chain. 

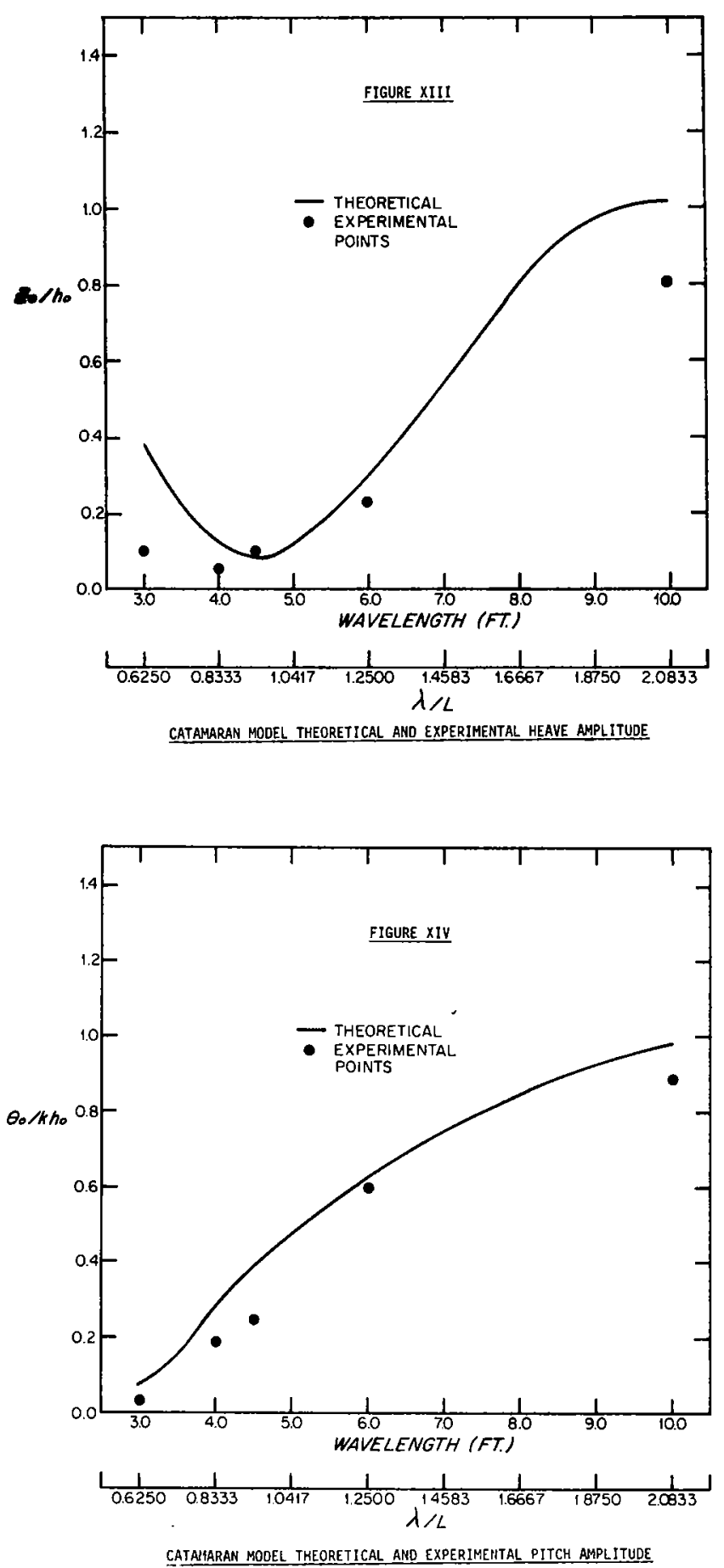

Figure 7. Cat amaran Mode1 Theoretical and Experimental Response Characteristics in a) Heave, and b) Pitch. (Reproduced from Booth 1967) 
The chain has a spring constant of 18 tons/inch, and four chains yield an equivalent spring constant of 72 tons/inch. With a combined weight for the cradle and ALVIN of 30 tons, the static elongation of the chain is less than .5 inches over 100 feet. The system was assumed to be inelastic for modeling purposes.

The chain which links the surface vessel and submerged platform can transmit only a tensile force. It was hypothesized that the cradle would follow the upward motion of the catamaran, while falling freely during downward motion. Since the chain is attached at two different longitudinal stations on the catamaran aft of mid-ships, different magnitudes of heave excitation should be expected on the leading and trailing edges of the cradle. This is to say that a coupled pitch and heave motion of the cradle should be observed.

A secondary forcing function is water particle motion caused by a progressive wave system. Newman (1971) defines a velocity potential for waves moving in the positive $\mathrm{X}$-direction as:

$$
\begin{aligned}
& \phi=\frac{g A}{\omega} \frac{\cosh k_{0}(z+h)}{\cosh k_{0} h} \cos \left(k_{0} x-\omega t+\delta\right) \\
& \text { where } k_{0}=\text { values of } k \text { which satisfy } k \text { tanh } k h=K=\frac{\omega^{2}}{g} \\
& z=\begin{array}{l}
\text { is measured negative downward from the } \\
\text { free surface }
\end{array} \\
& A=1 / 2 \text { peak to trough wave height } \\
& h=\text { depth of water } \\
& \delta=\text { arbitrary phase angle }
\end{aligned}
$$

The orbital motions of individual fluid particles in their wave 
system separated into horizontal and vertical components are:

$$
\begin{aligned}
& u=\frac{d \phi}{d x}=-\frac{g A}{\omega} k_{0} \frac{\cosh k_{o}(z+h)}{\cosh k_{0} h} \operatorname{in}\left(k_{0} x-\omega t+\delta\right) \\
& w=\frac{d \phi}{d z}=-\frac{g A}{\omega} k_{0} \frac{\sinh k_{0}(z+h)}{\cosh k_{0} h} \cos \left(k_{0} x-\omega t+\delta\right)
\end{aligned}
$$

These two velocity components are $90^{\circ}$ out of phase, and as $z \rightarrow-\infty$ these relations become equal such that water particles move in circular orbits of radius $A e^{K Z}$ where $A$ is one half the peak to trough wave height, and $K=\omega^{2} / g$. The radius decreases exponentially with depth, such that at depths greater than half a wave length $\left(\mathrm{e}^{\mathrm{KZ}}=\mathrm{e}^{-\pi}=.04\right)$, no significant particle motion occurs. If the depth of water is not infinite, but relatively shallow $(\mathrm{h}<\lambda / 2)$, the particle orbits become more and more elliptical, until in the limit, motion is purely horizontal. Water particle motion is not a significant excitation force acting on the cradle for this study because, the cradle is suspended at 100 feet and wave lengths in excess of 200 feet occur predominantly in sea states greater than sea state 5 (see Figure 4).

The simplest modification to the cradle/hoist system which would decouple catamaran pitch from the cradle would be reducing the number of cables from two forward and two aft, to two centered on the port and starboard sides of the cradle. Although this eliminates cradle pitch, it does not decouple heave. The effect of such an alteration on the influence of ALVIN, cradle lift, or air/sea interface characteristics must be the subject of further investigation. It should be noted, that my study deals with the 
cradle suspended at a depth of 100 feet below LULU without ALVIN attached or in near proximity.

The next modification investigated is the effect of changing different parameters on a damped, spring/mass system. Heller and Motherway (1971) offer the following mode1 for such a system.

Figure 8 represents a schematic of the catamaran, chain, and cradle system. If this analysis is to yield insight into attractive system modifications, the chain (or other hoist mechanism) must be assumed to be elastic.

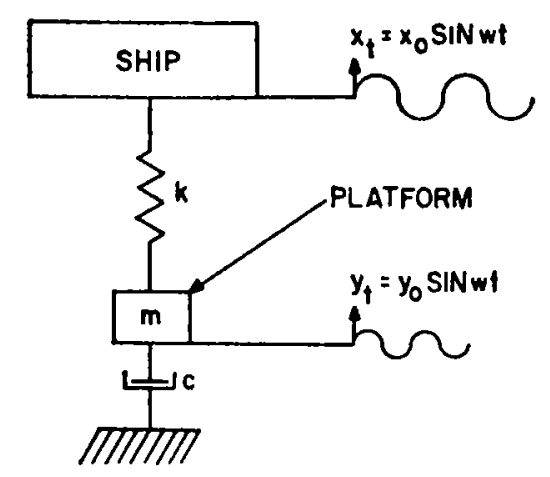

$$
\begin{aligned}
k= & \text { EQUIVALENT SPRING CONSTANT } \\
c= & \text { VISCOUS DAMPING OF CRADLE } \\
& \text { WITH SURROUNOING SEA }
\end{aligned}
$$

Figure 8 Schematic Catamaran-Chain-Cradle System

The differential equation for this system is:

$$
\ddot{M y}+\dot{C y}+k y=k x_{o} \sin \omega t
$$

where

$C$ is the damping coefficient of the cradle

$k$ is the equivalent spring constant of the connecting line

$M$ is the mass of the cradle plus its added mass $\left(m+m_{a}\right)$

$x_{0}$ is the amplitude of ship vertical motion

$y$ is cradle vertical motion (+ upward)

Based on the assumption of small vertical velocity of the 
cradle, a linear approximation for the damping yields:

$$
C=\frac{4_{\rho} A_{c} C_{d} Y_{o} \omega}{3 \pi}
$$

where

At is the projected area of the cradle normal to the flow

$\mathrm{C}_{\mathrm{d}}$ is the coefficient of viscous drag

$\mathrm{Y}_{\mathrm{O}}$ is the amplitude of the platform verticle motion

The standard solution of Equation (5) is:

$$
y=\frac{k x_{0} \sin \omega t}{\left[\left(k-M \omega^{2}\right)^{2}+(C \omega)^{2}\right]^{\frac{1}{2}}}
$$

or

$$
y_{0}=\frac{k x_{0}}{\left[\left(k-M \omega^{2}\right)^{2}+(C \omega)^{2}\right]^{\frac{1}{2}}}
$$

Applying the relation for undamped natural frequency of a single degree of freedom system:

$$
\omega_{n}=(k / M)^{\frac{1}{2}}
$$

Equation (7a) may be simplified to:

$$
y_{0}=\frac{x_{0}}{\left\{\left[1-\left(\frac{\omega}{w_{n}}\right)^{2}\right]^{2}+\left(\frac{C}{M \omega_{n}}\right)^{2}\left(\frac{\omega_{w}}{w_{n}}\right)^{2}\right\}^{\frac{1}{2}}}
$$

Substituting Equation (6) into Equation (7b) and performing additional algebraic manipulation results in the following:

$$
\left(\frac{4 \rho A_{c} C_{d}}{3 \pi M}\right)\left(\frac{\omega}{\bar{\omega}_{n}}\right)^{4} y_{0}{ }^{4}+\left[1-\left(\frac{\omega}{\omega_{n}}\right)^{2}\right]^{2} y_{0}{ }^{2}-x_{0}{ }^{2}=0
$$

The typical solutions to Equation (9) are represented in Figure 9. The important trend to note is that: (1) in all damping situations, where the system is excited above two times the undamped natural 


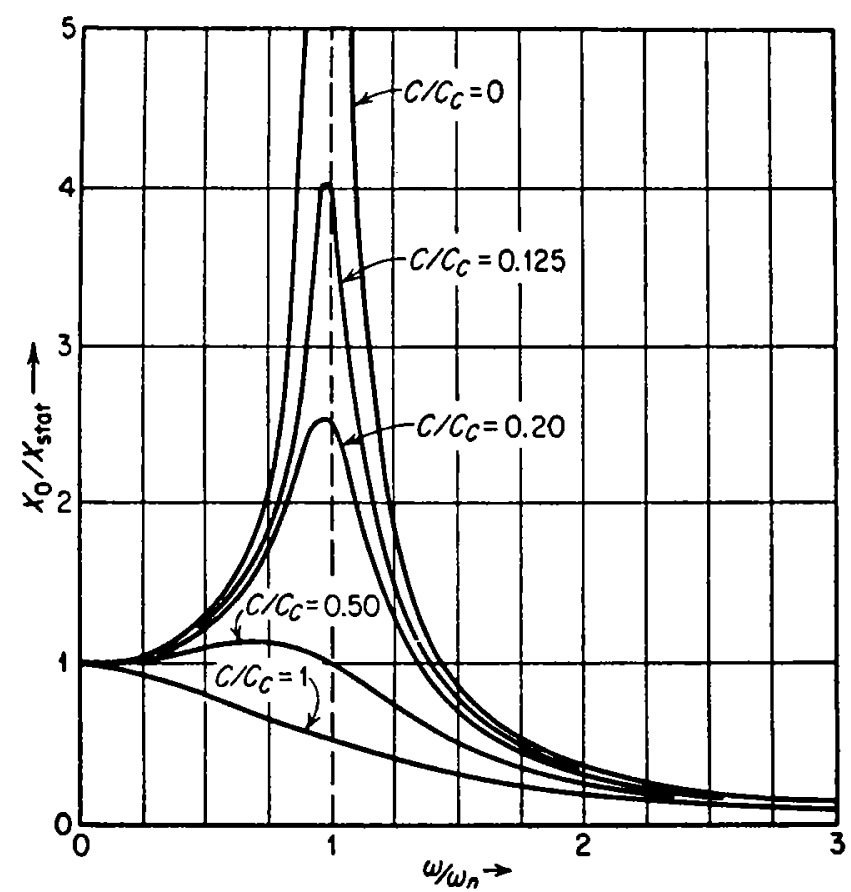

(a)

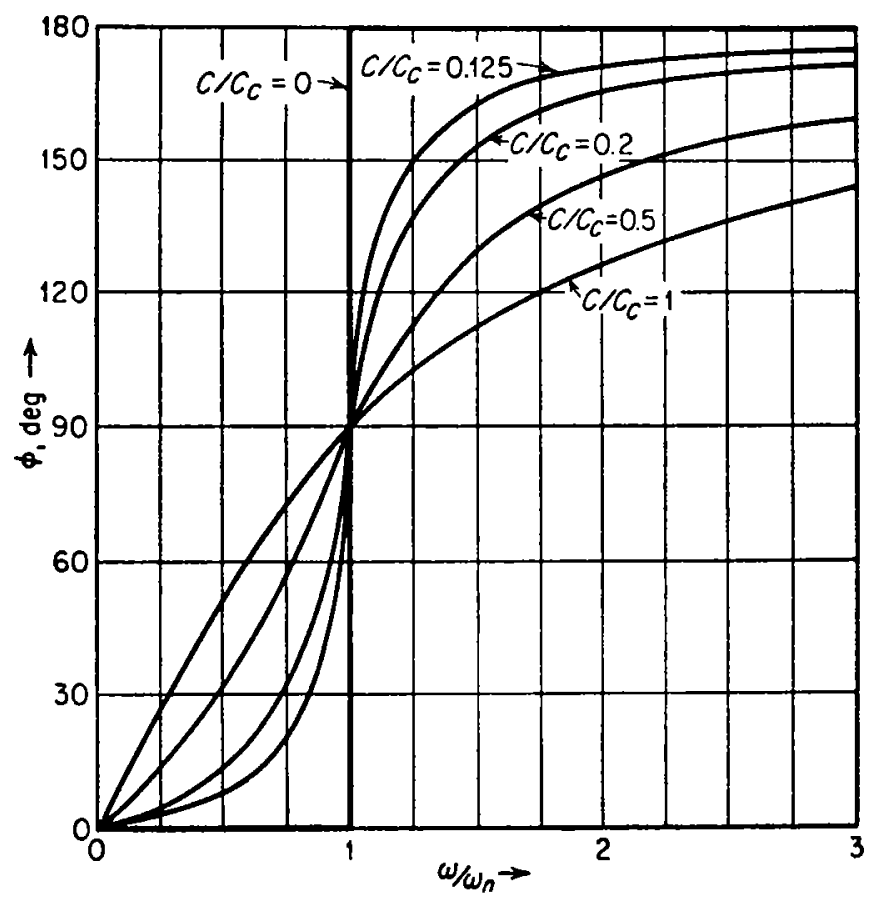

(b)

Figure 9. Single Degree of Freedom a) Forced Vibration Amplitude, and b) Phase Angle Between Force and Displacement. (Reproduced from Den Hartog (1956). 
frequency, response is less than one half the input; and (2) at such high frequencies, the phase difference in ship/cradle motion is in excess of $130^{\circ}$. Simply then, if two conditions can be met in the just described single degree of freedom system, cradle motion can be significantly reduced over catamaran heave: First, by increasing the resiliency of the hoist system (decrease the spring constant) and increasing the added mass of the cradle, the undamped natural frequency can be lowered to such a point that catamaran motion is sensed only as high frequency noise by the stabilized cradle. Secondly, because the phase difference is so great between ship and cradle motion, the hoist system must have sufficient resiliency to permit elongation of 10 per cent in sea state 4, thereby accounting for the difference in motion. Figure 10 shows sea spectra for sea states 4 and above. Based on this figure, if the cradle system can be designed for a natural frequency of $\omega_{n}=.2 \mathrm{rad} . / \mathrm{sec}$. , then cradle heave will be less than one half catamaran heave for $\omega / \omega_{n}>2$. Assume the full scale cradle has a mass of 508 slugs (see Table II) and a flat plate across the bottom of the cradle of equal mass gives it an added mass of 7175 slugs, the spring constant necessary for $\omega_{n}=.2 \mathrm{rad} . / \mathrm{sec}$. is:

$$
\begin{aligned}
\omega_{n} & =(\mathrm{k} / \mathrm{M})^{\frac{1}{2}} \\
k & =\omega_{n}{ }^{2} \mathrm{M} \\
& =(.2)^{2}(508+508+7175) \\
& =(.04)(8191) \\
k & =328 \mathrm{lbs} . / \mathrm{ft} .
\end{aligned}
$$

With a combined cradle/plate weight of 32,556 pounds, this would mean a static spring hoist deflection of 100 feet. Obviously 

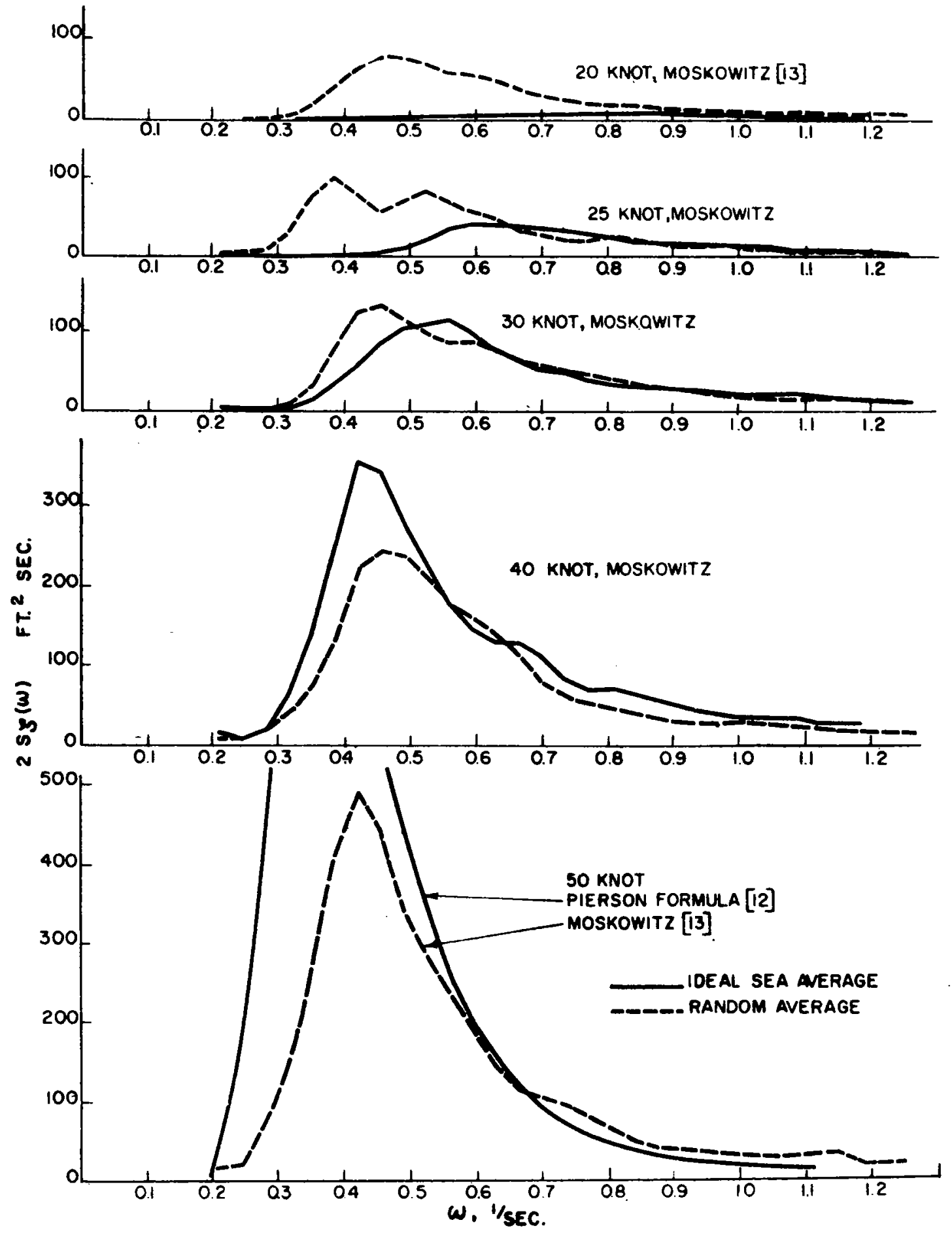

Figure 10. Comparison of Moskowitz Family of Sea Spectra Obtained by Random Sampling with Family of Ideal Average Spectra. (Reproduced from Comstock and Lewis 1968). 
this is impractical and unacceptable in a system which is designed for a depth of 100 feet. Without increasing the natural frequency, hence cradle response, if the cradle mass were halved to 254 slugs, and the same added mass of 7175 slugs was provided by a light parachute drogue (6 slugs) hung from the cradle; the spring constant now required is:

$$
\begin{aligned}
k & =(.04)(254+7175) \\
& =(.04)(7429) \\
k & =297 \text { pounds } / \text { foot }
\end{aligned}
$$

The static cradle deflection is 28 feet, a more reasonable value.

The above exercise was designed to give the reader a feel for the problems involved in a passive design to decouple ship cradle motion. I feel that improvements in the overall system can be accomplished by one or a combination of several means:

1) Reduction of the in-water weight of the cradle to reduce static spring deflection to under 10 feet. This can be accomplished by means of cradle design having only a slight negative buoyancy.

2) Maximize the hydrodynamic added mass of the cradle by either dynamic thrusters which are acceleration sensitive; a venetian blind type plate, which would offer minimum drag during cradle hoisting, while offering flat plate added mass characteristics during mating; detachable parachute hung beneath the cradle to be jettisoned upon ALVIN/cradle mating; or a combination of the above.

3) A small but simple improvement proposed which does not require an alteration of the existing system is having 
LULU make headway, such that a catenary forms in the four hoist chains. This catenary is translated into an equivalent spring, since ship motion at the top of the chain is attenuated in part by the cable straightening as the tension in the line is increased overcoming in part the effects of hydrodynamic drag.

The areas of investigation in this thesis are therefore:

1) Response of the unaltered ship/chain/cradle system with no way on.

2) Effects of forward speed on the response of the cradle

3) Effects of changes in spring and added mass characteristics

4) Effects of suspension alteration from four point to two point suspension on cradle response.

The following section will describe how these experiments were accomplished. 


\section{FABRICATION AND PROCEDURE}

Model construction and test procedures were designed to be compatible with the M.I.T. Tow Tank Testing Facility which was the most convenient and available facility for the series of experiments. The tow tank is 108 feet long, 9 feet wide, and 4 feet deep, with 26 feet of glass along its outer wa11. At one end it has a hydraulically driven metal plate wavemaker hinged at the bottom of the tank. Plate motion is controlled either by an electrical oscillator for making regular sinusoidal waves, or by a tape deck for generation of preprogrammed random seas. Wave amplitude is controlled by the stroke of the wave maker. At the opposite end of the tank is a beach consisting of bailed metal filings which act to dissipate wave energy with minimum reflection. Models are propelled via an overhead carriage which is driven at constant speed by means of a continuous steel tape. The model is attached to the carriage through a combination heave rod/pitch bearing assembly. The heave rod floats in air bearings to minimize system friction. Model pitch and heave are recorded electrically on strip chart paper from outputs provided by a rotary variable differential transformer on the pitch bearing and a linear differential transformer on the heave rod assembly respectively. Waveheight is measured by means of a two-wire resistance probe and recorded on the same strip chart.

Given the depth of the tow tank as 48 inches, and the requirement to test the cradle at a scale depth of 100 feet below the surface, model scale was set at $1 / 40$ full scale size. This placed the eradle at a depth of 30 inches in the tank, leaving 18 inches 
clearance above the bottom to avoid hydrodynamic interference.

Kenny (1969) provided half size drawings of a $1 / 20$ scale model of LULU, which were used directly as templates for my model. Carl

S. Albro, a fellow student in the joint MIT-WHOI Ocean Engineering Program constructed a very accurate $1 / 40$ scale model of the cradle. Jewlers chain was obtained which scaled the full scale chain in both gross dimension and mass distribution. (Figures 11, 12, and

13) A summary of full scale and model characteristics is listed

in Table II. (See Appendix A for determination of radius of gyration.

Table II

Full Scale and Model Characteristics

$1 / 40$ Scale

\begin{tabular}{|c|c|c|c|}
\hline & ITEM & FULL SCALE & MODEL \\
\hline $\begin{array}{l}\mathrm{C} \\
\mathrm{A} \\
\mathrm{T} \\
\mathrm{A} \\
\mathrm{M} \\
\mathrm{A} \\
\mathrm{R} \\
\mathrm{A} \\
\mathrm{N}\end{array}$ & $\begin{array}{l}\text { Length, L (ft.) } \\
\text { Beam overall (ft.) } \\
\text { Beam, each hull (ft.) } \\
\text { Displacement (lg. ton/lbs) } \\
\text { Long. C.G. aft of F.P. (ft) } \\
\text { Long. Rad. of Gyration (ft) }\end{array}$ & $\begin{array}{r}96 \\
48 \\
14 \\
437 \\
\\
48 \\
28.9\end{array}$ & $\begin{array}{l}2.4 \\
1.2 \\
.35 \\
15.3 \text { (includes heave } \\
1.2 \text { rod/pitch brg.) } \\
.72\end{array}$ \\
\hline $\begin{array}{l}\text { C } \\
\text { R } \\
\text { A } \\
\text { D } \\
\text { L } \\
\text { E }\end{array}$ & $\begin{array}{l}\text { Length, } L(f t) \\
\text { Width (ft) } \\
\text { Weight (Dry) (Lg.ton/1bs) }\end{array}$ & $\begin{array}{r}17.5 \\
16.3 \\
7.3\end{array}$ & $\begin{array}{l}.4375 \\
.4083 \\
.2555\end{array}$ \\
\hline $\begin{array}{c}\mathrm{C} \\
\mathrm{H} \\
\mathrm{A} \\
\mathrm{I} \\
\mathrm{N}\end{array}$ & $\begin{array}{l}\text { Length, } L \text { (ft) } \\
\text { Width, (in) } \\
\text { Weight (Dry) (lbs) }\end{array}$ & $\begin{array}{r}100 \\
4 \\
1000\end{array}$ & $\begin{array}{l}2.5 \\
.1 \\
.0156\end{array}$ \\
\hline
\end{tabular}




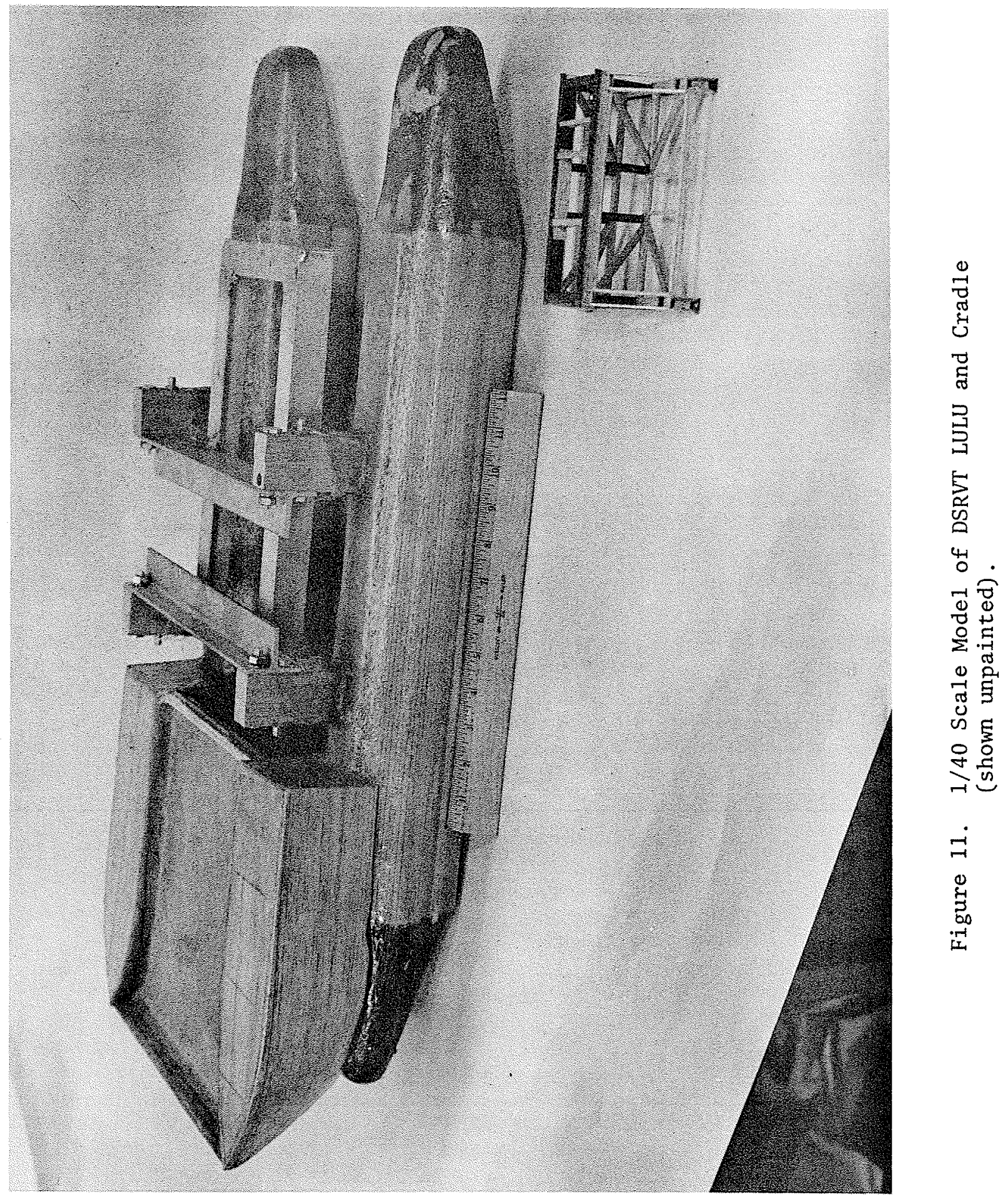



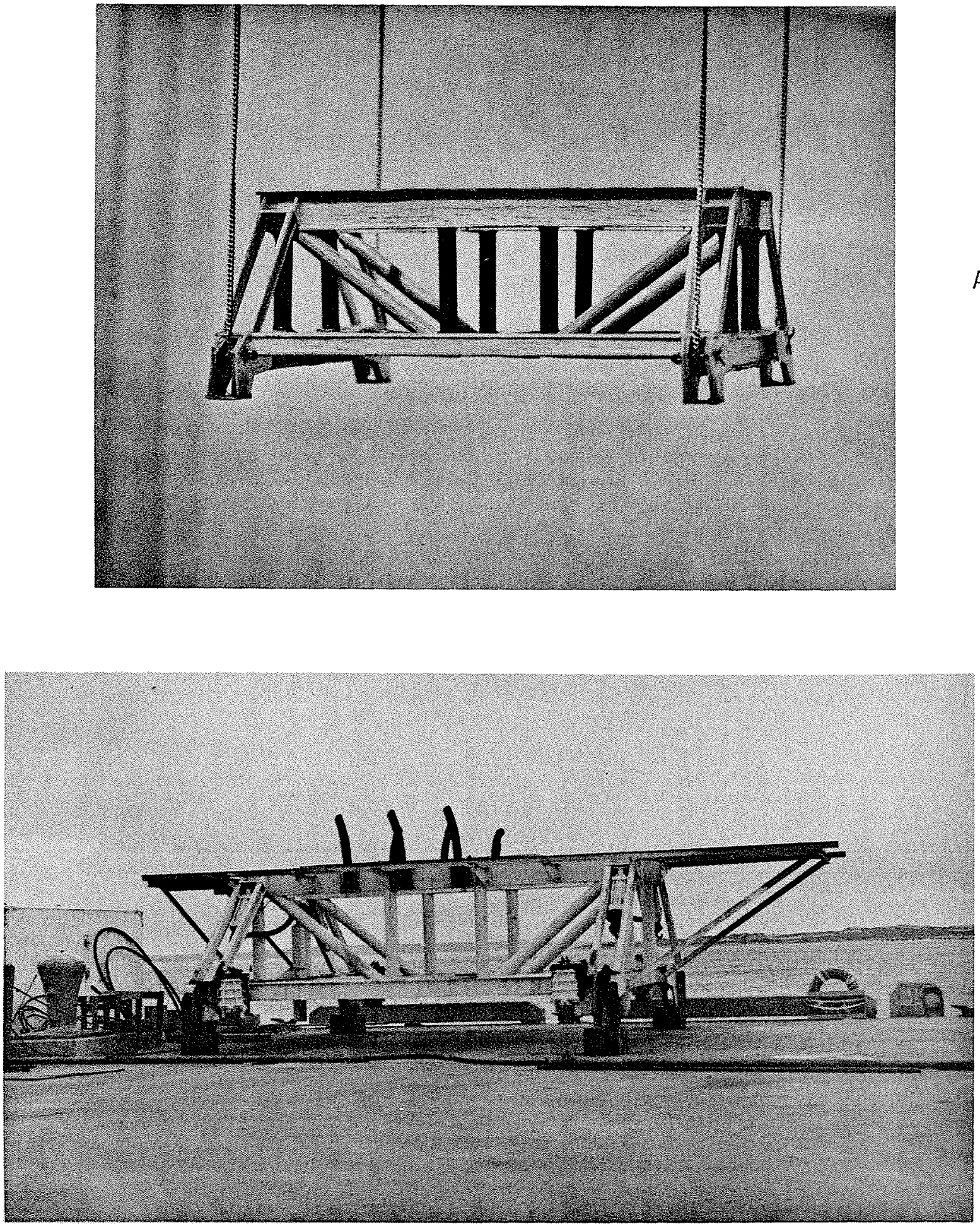

Figure 12. Recovery Cradle a) Model with Scale Chain, and b) Full Scale with Surface Support Structure. 


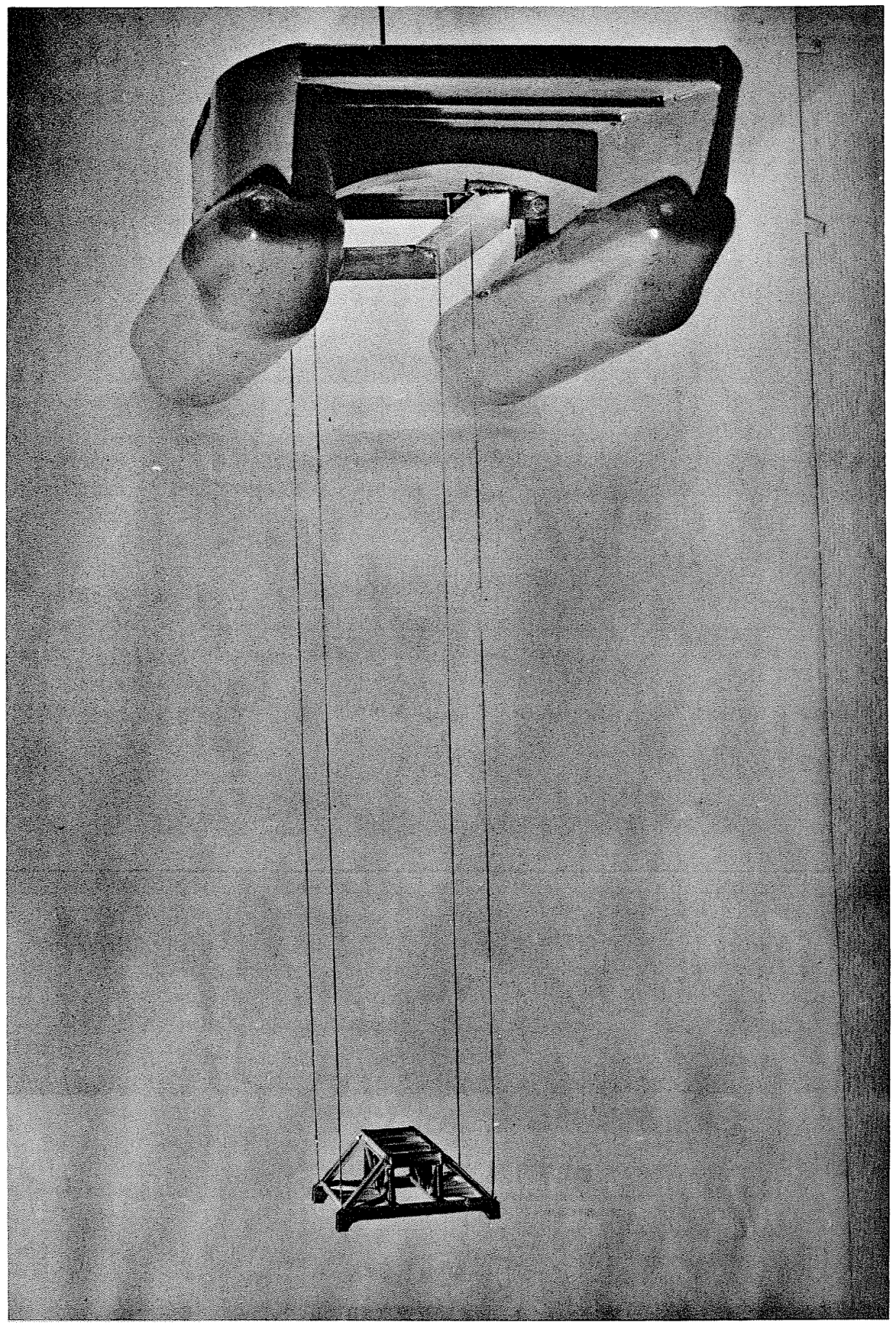

Figure 13. Model Cradle Suspended 30 Inches Beneath Catamaran via Four-Point Chain Suspension. 
Whereas wave height and catamaran motion could be easily recorded on strip chart paper, the sma11 weight of the cradle (116 grams) made any addition of motion sensing or recording instrumentation highly undesirable since it would significantly alter the dynamic characteristics of the cradle. An acceptable alternative to direct instrumentation was photographic recording of cradle motion, synchronized to catamaran records by including a watch in thelfield of view of the motion picture camera. As the sweep second hand passed the 5 second mark, an observer would close a handheld switch making a mark on the strip chart. This time base correlation is critical to phase and relative motion analysis. In order to assure correct length scale during later projection and data reduction, a steel tape measure scale was included directly below the cradle, where it also served as a visual baseline from which to measure cradle heave. This steel measure was attached to the tow carriage with a steel rod so that it was unaffected by wave motion. (Figure 14)

Experiments were conducted with the model stationary and moving, so that the camera had to be able to follow the action. An aluminum frame consisting of $3 / 4$ inch 6061 pipe joined with detachable Nu-Rail fittings was constructed, and attached to the carriage with pipe clamps, (Figure: 15). This setup proved quite satisfactory as it was easily assembled and disassembled, providing the necessary range of adjustable members. Additionally, it was easy to transport in a passenger car between Woods Hole and M.I.T., and did not require alteration of the tow tank carriage 


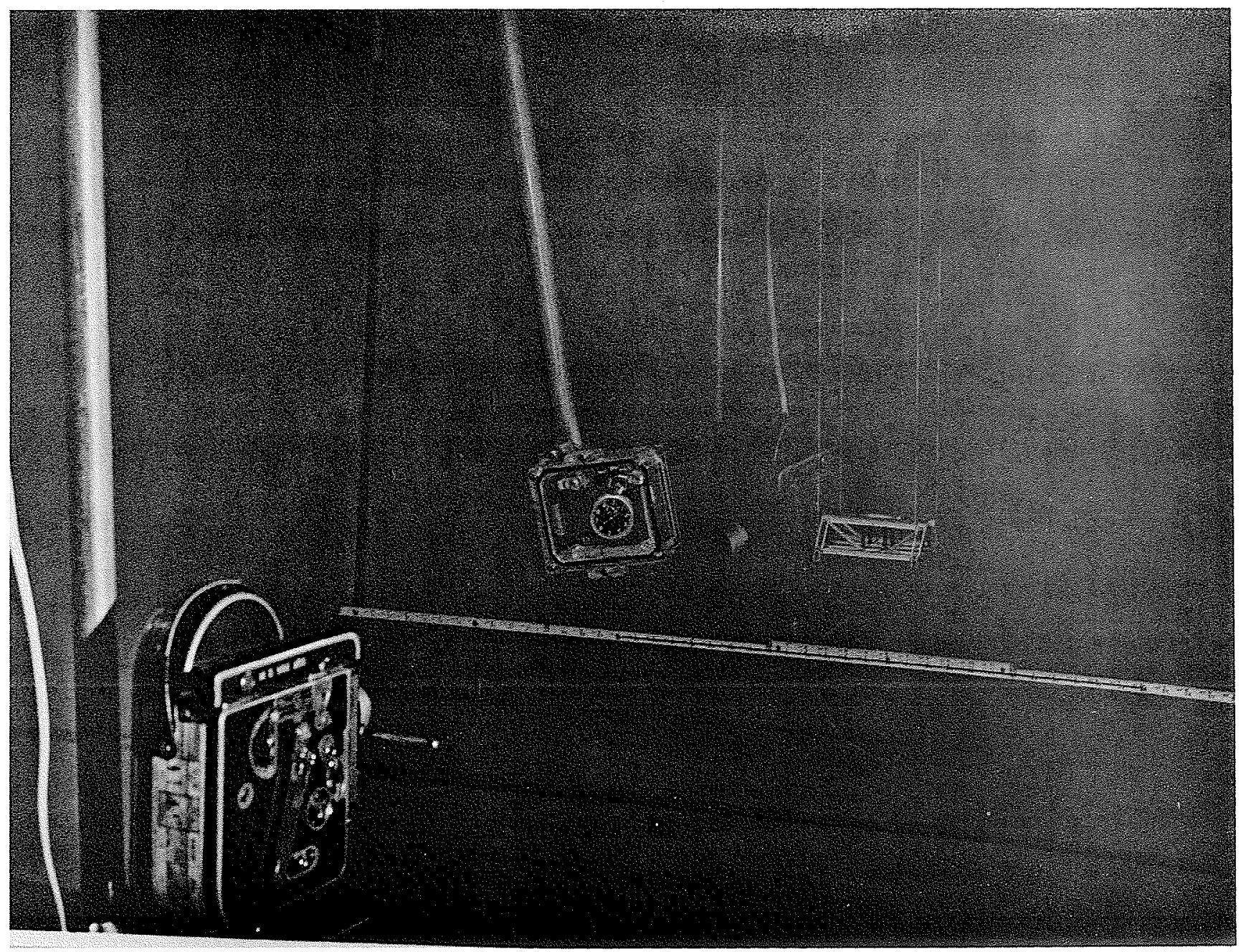

Figure 14. Data Taking Equipment Arrangement Showing Camera, Light, and Stopwatch in Foreground; Catamaran, Cradle, and Scale in Background. 

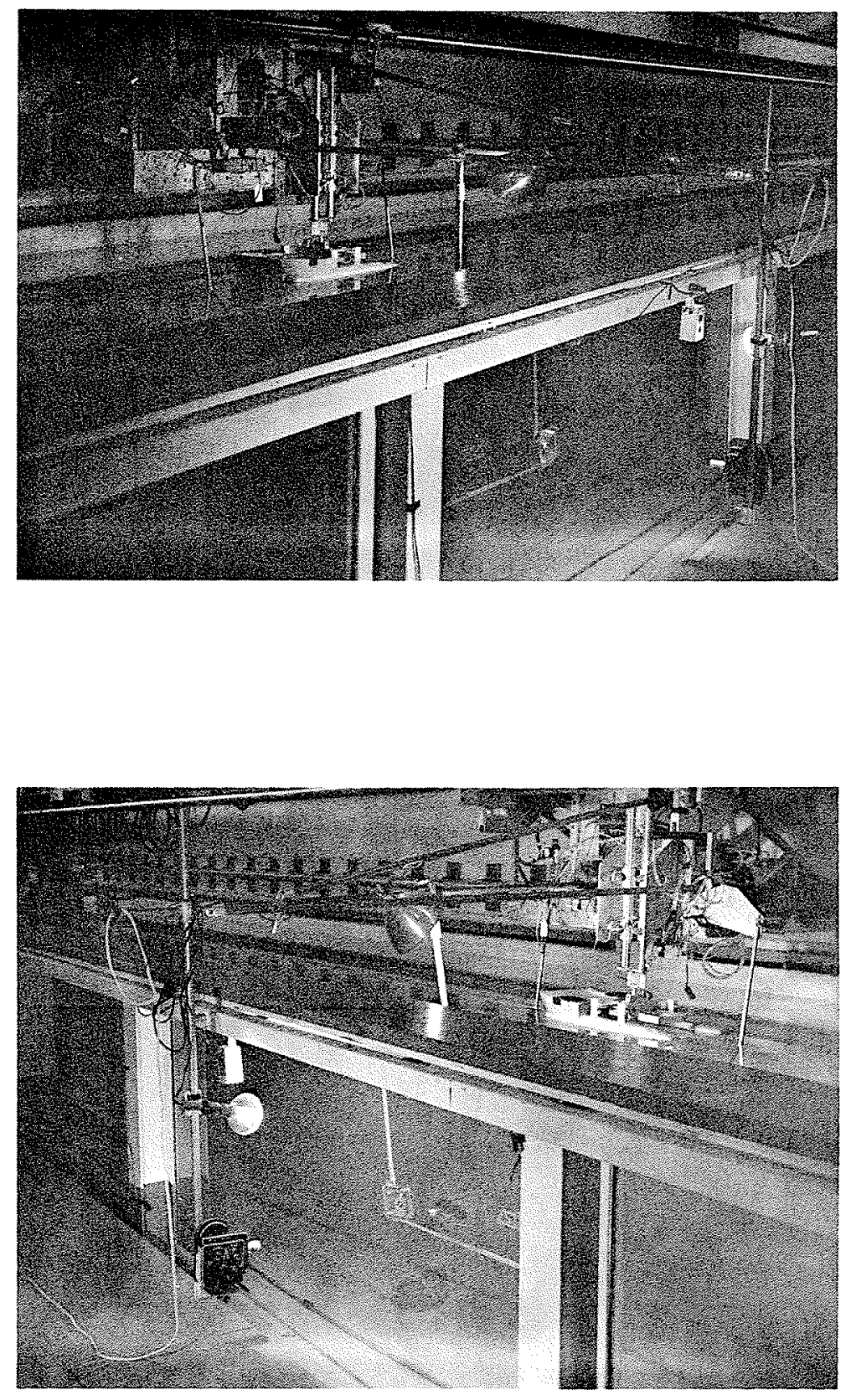

Figure 15. Overal1 Equipment Arrangement at M.I.T. Tow Tank Showing a) Bow View, and b) Stern View. 
for installation. A Bolex reflex $16 \mathrm{~mm}$ motion picture camera, with a 100 foot film capacity was obtained from William Von Arx of Woods Hole Oceanographic Institution. Using a $15 \mathrm{~mm}$ lens, Kodak 4x reversal film (ASA 320), and two photographic spot lights mounted on the aluminum frame for a camera setting of f5. 6 at a speed of $16 \mathrm{fps,} 600$ feet of data were recorded under the skilful hand of photographic specialist Claude Ronne of the Woods Hole Oceanographic Institution. A representative sequence of cradle motion is included (Figure 16). The actual rolls of data are with Jim Mavor of W.H.O.I.

- With model and recording devices complete, tests were conducted at the M.I.T. Tow Tank. The scope and results of those tests are discussed in the following section. 

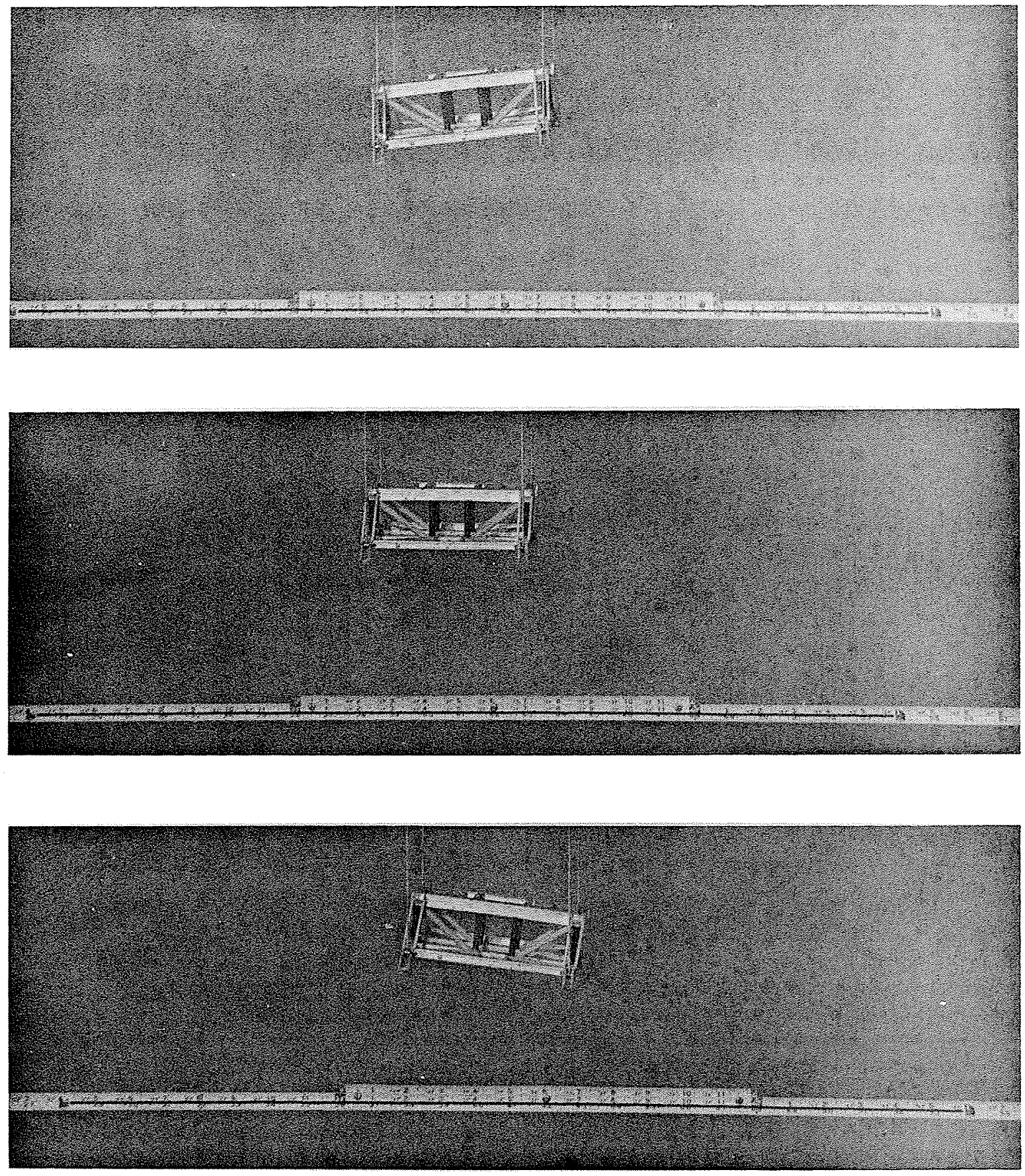

Figure 16. Representative Sequence of Cradle Motion (Catamaran Bow Pointing Left). 


\section{RESULTS}

Eighty-one individual tow tank tests were conducted using the previously described $1 / 40$ scale model of LULU, her chain, and cradle. Forty-two tests were conducted on the unmodified system such that the cradle was suspended 30 inches below LULU by means of four scale chains attached at each corner. Four tests were conducted on the unmodified system with the cradle suspended at a depth of 15 inches to investigate pendulum resonance. Twenty tests involved modification of the cradle by addition of a flat plate to the bottom of the cradle and the placement of springs at each corner between the chain and cradle support points (Figure 17). Fifteen tests were conducted using the modified cradle at a depth of 30 inches, but with a two point port and starboard spring suspension having an equivalent spring constant of one-fourth the four point spring system (Figure 18).

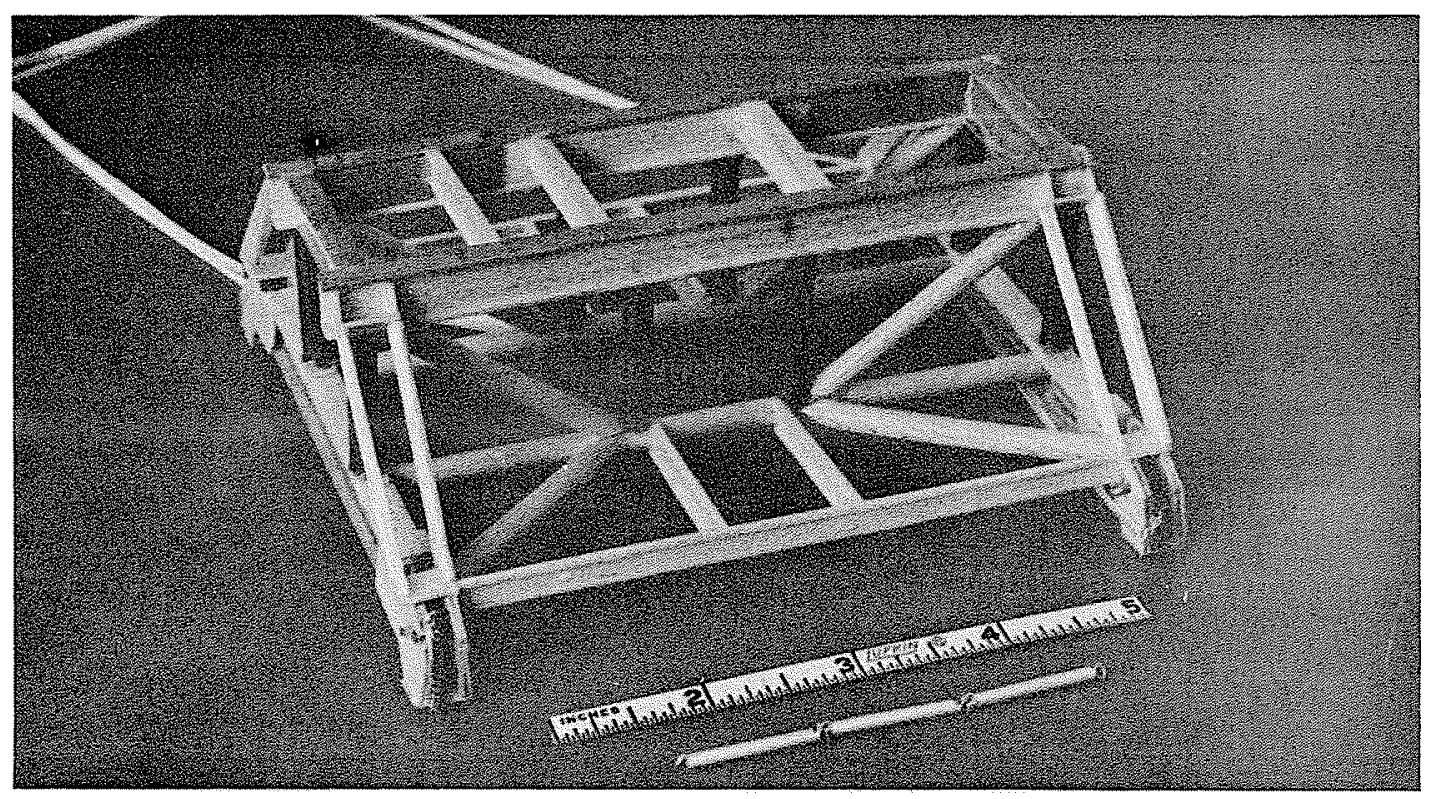

Figure 17. Model Cradle Showing Spring Detail. 


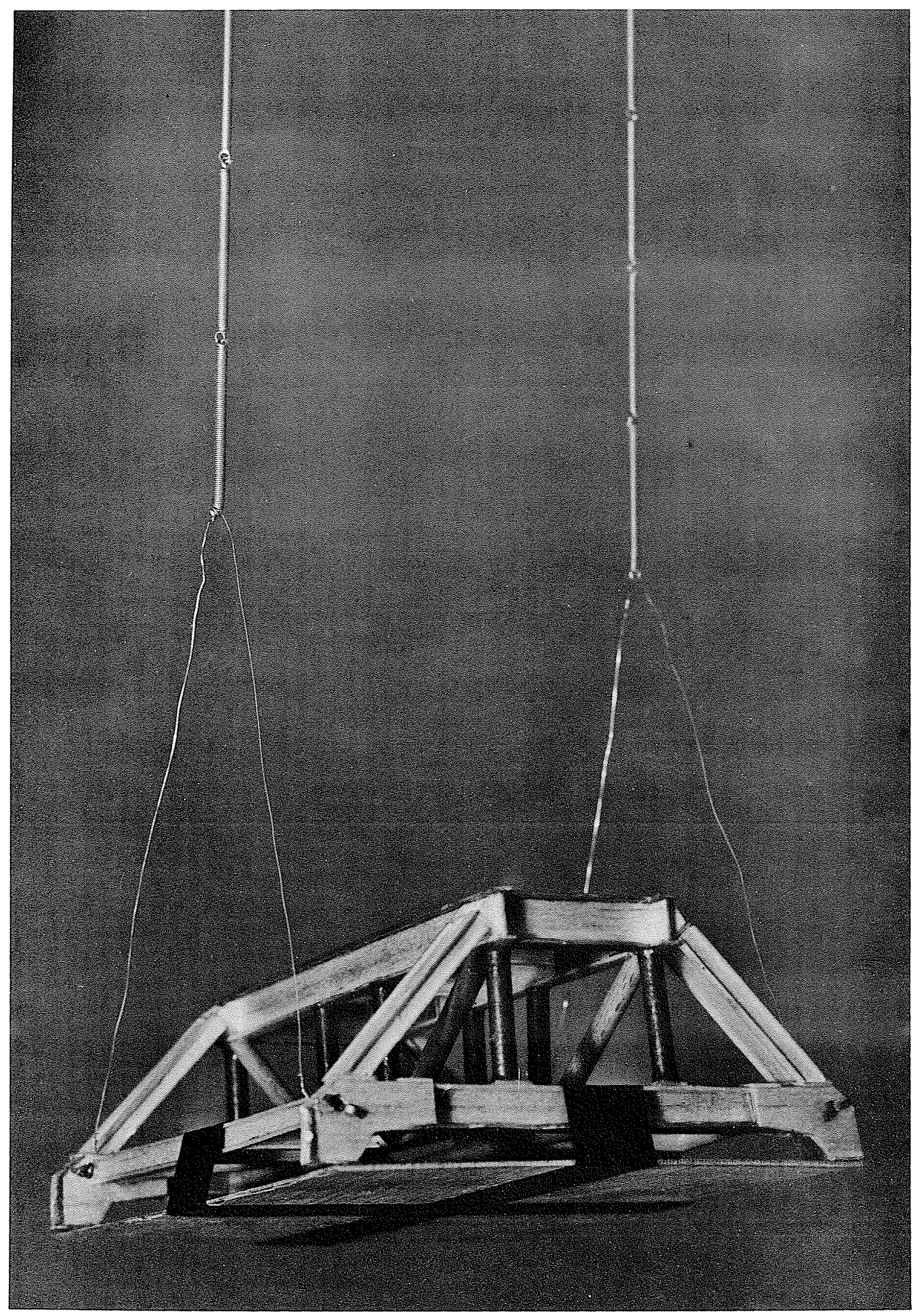

Figure 18. Model Cradle Alteration with Two Point Spring Suspension and Flat Plate. 
As mentioned earlier, cradle motion response data consisting of 600 feet of $16 \mathrm{~mm}$ film were recorded. The film was projected on a full scale grid by means of a time/motion study projector from which heave of the leading and trailing edges of the cradle, as well as pitch and trail angle were reduced. With the exception of trail angle (which is included here) the results are summarized in Appendix B. The run number refers to the code recorded on the film to designate the beginning of a test. Numbers 1 thru 46 represent the unaltered system (cradle suspended at 15 inches for runs 33, 34, 35, and 36). Runs 101 thru 120 are for a four point spring suspension, with flat plate attached to the cradle. Runs 121 thru 135 cover the two point spring suspension with flat plate as before (note that cradle pitch was insignificant).

The objective of this study was to determine the response of the recovery system in a state 4 sea, hence tests were conducted in regular waves at a full scale wave height of 8.5 feet. This represents the mean of the one tenth highest waves in a sea state 4 , and scales to a tow tank wave height of 2.55 inches. Additionally, nearly all tests were run at a model wave height of 1 inch to check the linearity of systems response. Mode1 wave lengths were set at $2,4,6,8$, and 10 feet in order to cover a range of $\lambda / L$ ratios. In the unmodified tests, wave lengths of 7.75 , 7.85 , and 9.69 feet were also used to excite the suspended cradle (which appears as a viscous damped pendulum). The 7.75 foot wave length represents the half harmonic natural excitation frequency at zero model speed for a 30 inch pendulum. The 7.85 
foot and 9.69 foot wave lengths represent the first harmonic natural excitation frequency for a 15 inch pendulum at model speeds of .207 and .498 knots respectively. Horizontal cradle displacement and surge oscillation information is summarized in Table III.

Table III

Summary of Horizontal Cradle Displacement and Cradle Surge Oscillation

\begin{tabular}{|c|c|c|c|}
\hline $\begin{array}{l}\text { MODEL } \\
\text { SPEED } \\
(k t s) \\
0 .\end{array}$ & $\begin{array}{c}\text { CRADLE } \\
\text { DEPTH } \\
\text { (inches) } \\
30\end{array}$ & $\begin{array}{c}\text { HORI ZONTAL }^{1} \\
\text { CRADLE } \\
\text { DISPLACEMENT } \\
\text { (inches) }^{\text {inch }} \\
0 \\
\end{array}$ & $\begin{array}{c}\text { CRADLE } \\
\text { SURGE } \\
\text { OSCILLATION } \\
\text { (inches) } \\
.5 \\
\end{array}$ \\
\hline .207 & 30 & 3 & .5 \\
\hline .207 & 15 & 1 & .25 \\
\hline .498 & 30 & 10 & 1.0 \\
\hline .498 & 15 & 2 & .25 \\
\hline .981 & 30 & 17 & 1.0 \\
\hline $.498^{2}$ & 30 & 4.5 & .25 \\
\hline
\end{tabular}

Figures $B 1$ thru $B 10$ represent the pitch and heave response of the model and cradle as tested. Figures B1 and B2 indicate that: 1) the heave response of LULU increases with increasing forward speed, 2) the response is nearly linear for wave heights up to 8.5 feet, and 3) the model was tested at its resonant frequency which varies from 5 to 7 radians per second depending upon model speed. Figures B3 and B4 indicate that: 1) overall, 
heave response of the trailing edge of the cradle increases with increasing forward speed to a maximum at .498 knots; however, at .981 knots the response is considerably reduced over the entire range of frequencies investigated: 2) the response is nearly linear for wave heights up to 8.5 feet with the exception of a 20 per cent difference at .207 knots, $\omega_{e}=8 \mathrm{rad} . / \mathrm{sec}$. , and a 40 per cent difference at .981 knots $\omega_{e}=7 \mathrm{rad} . / \mathrm{sec}$; and 3 ) resonance was observed between frequencies of 5 and 8 radians per second. Figures B5 and B6 indicate that: 1) catamaran pitch response tends to increase with increasing forward speed, 2) the response is nearly linear for wave heights up to 8.5 feet with the exception of a tuned phenomena at frequencies around 8 radians per second in the higher wave height experiments, and 3) resonance was observed between frequencies of 7 and 9 radians per second. Figures $B 7$ and B8 indicate: 1) pitch response tends to decrease with increasing speed up to a speed of .498 knots for a model wave height of 1 inch, while increasing with speed for model wave height of 2.5 inches; 2) the response does not appear to be linear over the range of frequencies tested; and 3) for the smaller wave height, a distinct resonance appears at a frequency of about 5 radians per second, while resonance occurs from 7 to 10 radians per second for the larger wave height situation. Figure B9 shows that the four point spring suspension with added plate yields a significantly worse response in heave than the unmodified situation due to resonant reinforcement. Note that for a given speed, response decreases with increasing wave height 
since viscous damping is amplitude dependent (Equation 6). The lower set of lines represents response of the two point suspension with added plate. The amplitude is significantly reduced for this range of frequencies; however, resonance has not been observed since it would occur at lower frequencies (longer wave lengths) than were investigated here. Figure $B 10$ represents pitch response of the modified cradle, which as in heave, is significantly greater than the unmodified system. There was no pitch variation noted for the two point suspension; however, a constant down angle of 6 degrees was recorded when the cradle was towed at .498 knots. Figure 19 gives the reader an idea: of the relative magnitude of wave height to ship response in a regular 8.5 foot wave. (Note bow and stern emergence, and rolling, breaking waves aft on the pontoon.)

No surge resonance was observed with the cradle at a depth of 15 inches. No yaw or sway instability was apparent up to tow speeds of .981 knots. With the exception of the four point spring suspension, the chain was not observed to go slack or kink. Cradle response overall was observed to be of greater magnitude (both pitch and heave) when the catamaran was lifting the cradle, than when the chains were eased, and the cradle fell of its own weight (indicating a no load condition at the lower end of the chain).

Cradle data for the two point suspension shown in Figure B10 has been replotted in Figure 20 along with curves representing solutions to Equation 9 for the following parameters: 

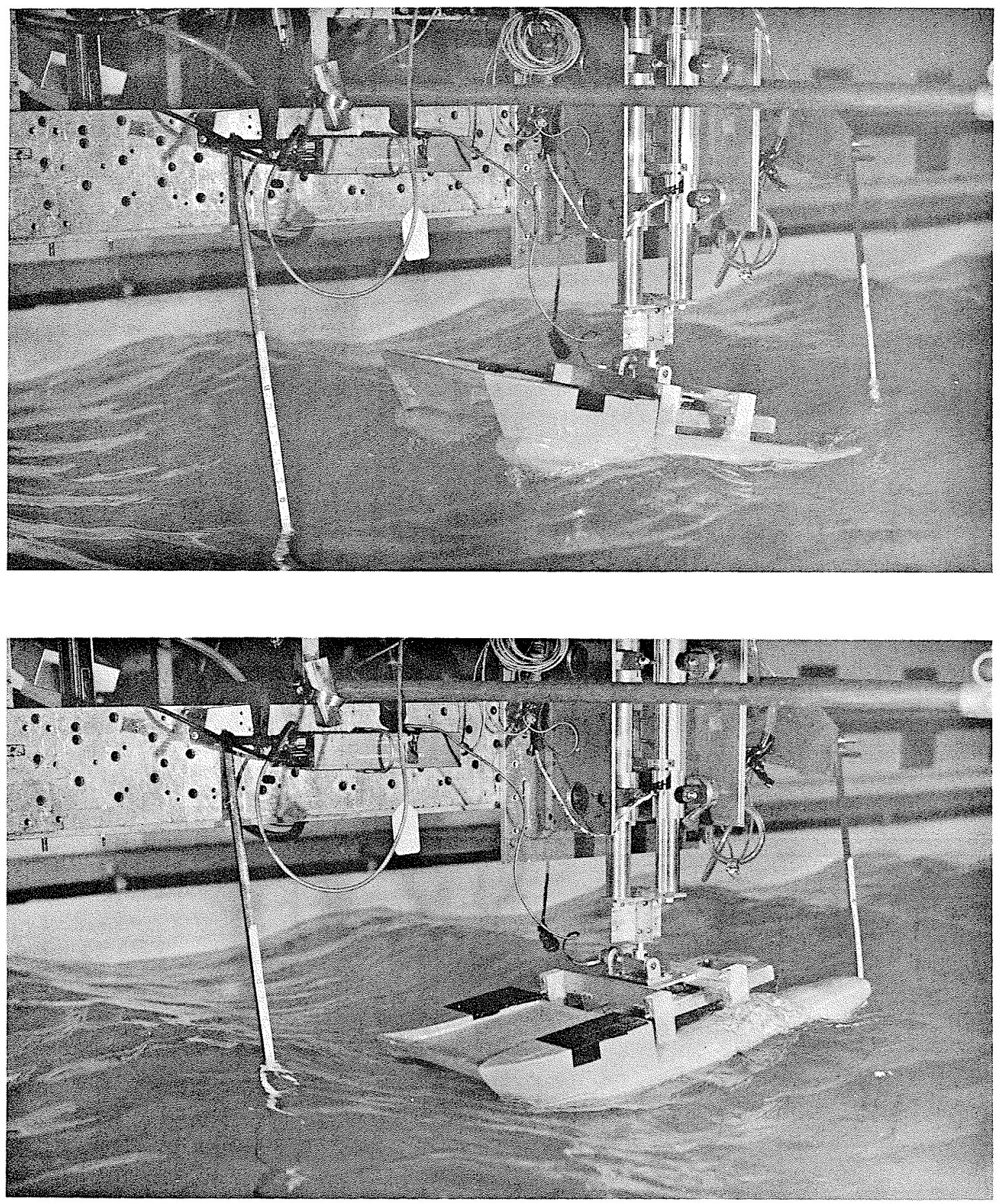

Figure 19. Catamaran Response in the Equivalent of 8.5 Foot High, 120 Foot Long Regular Waves Full Scale. 


$$
\begin{aligned}
& \text { mass of cradle with plate (m):,01656 slugs } \\
& \text { plate dimensions: } 4.75^{\prime \prime} \times 5.5^{\prime \prime} \\
& \text { added mass of cradle with plate: } \\
& \mathrm{m}_{\mathrm{a}}=\pi \mathrm{r}^{2} \mathrm{~L} \mathrm{\rho} \\
& =\frac{(3.14)(2.375)^{2}(5.5)(1.94)}{1728} \\
& =.10936 \text { slugs } \\
& M=m+m_{a}=.1259 \text { slugs } \\
& \text { cradle damping with plate: } \\
& C=\frac{4 \rho A_{c} C_{d} Y_{o}{ }^{\omega}}{3 \pi} \\
& =(4)(1.94)(4.75)(5.5)(1.16) y_{0} w \\
& \text { (3) }(3.14)(144) \\
& C=.1503 \mathrm{y}_{0} \omega
\end{aligned}
$$

equivalent spring constant (k): $1.24 \cdot 1 \mathrm{bs} / \mathrm{ft}$

natural frequency:

$$
\begin{aligned}
\omega_{n} & =(\mathrm{k} / \mathrm{M})^{\frac{1}{2}} \\
& =(1.24 / .1259)^{\frac{1}{2}} \\
\omega_{n} & =3.138 \mathrm{rad} . / \mathrm{sec} .
\end{aligned}
$$

hence:

$$
\left(\frac{4 \rho A_{c} C_{d}}{3 \pi M}\right)\left(\frac{\omega}{\omega_{n}}\right){ }^{4} y_{o}^{4}+\left[1-\left(\frac{\omega}{\omega_{n}}\right)^{2}\right]^{2} y_{0}-x_{0}^{2}=0
$$

becomes :

$$
.0142 \omega^{4} y_{0}^{4}+\left(1-.102 \omega^{2}\right)^{2} y_{0}^{2}-x_{0}^{2}=0
$$

Curves $a, b$, and $c$ represent values of $x_{0}$ equal to 1 inch, 1.581 inch, and 2.5 inch respectively. Experimental and theoretical agreement is good. 


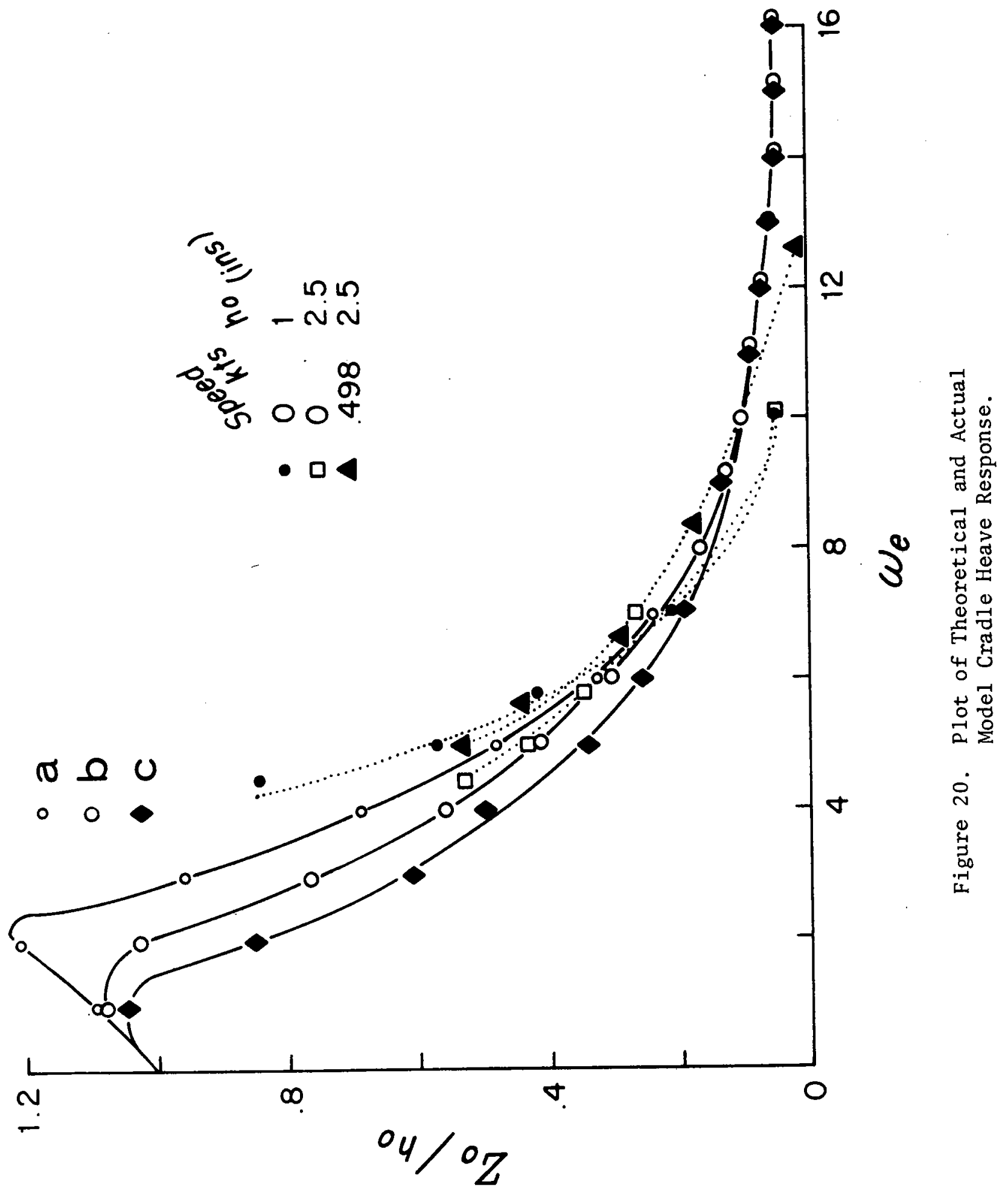


DISCUSSION OF RESULTS

The data presented in the previous section coverha wide range of ship speeds, wave heights, wave lengths, and basic passive alterations to the chain/cradle system. In almost all cases, a resonant condition was observed within the range of frequencies used in this study, so that the worst response to be expected was documented. As stated earlier (Hoerner, 1965) the drag coefficient for flat plates does not vary significantly for Reynolds' numbers greater than 100. Since cradle size/vertical. velocity yielded a Reynolds' number on the order of $10^{3}$, and full scale is on the order of $10^{5}$, Froude scaling for size is valid and mdoel results should be considered to be applicable to the full scale situation. 


\section{CONCLUSIONS}

Based upon the data obtained in this investigation, the following conclusions may be drawn.

1) As presently configured, cradle heave at a depth of 100 feet is only slightly attenuated over catamaran heave for forward speeds of less than 3 knots. Cradle heave is nearly half catamaran heave at 6 knots.

2) Cradle pitch response for the existing system is only slightly attenuated over catamaran response.

3) Full scale cradle heave in regular 8.5 foot waves would fal1 somewhere between 1 foot for high ship speeds, and wave lengths shorter than ship length, and 9 feet for slower ship speeds and wave lengths three or more times ship length.

4) Cradle pitch will vary from less than one degree to more than 20 degrees for the unaltered system.

5) It is possible to alter cradle response significantly (for better or worse) in both heave and pitch by changing the spring constant of the hoist, and by changing the added mass of the cradle.

6) It is possible by various means already discussed (i.e. 
cradle weight reduction, venetian blind plate, jettisonable drogue, roller springs) to drive the natural frequency of the cradle low enough, so that response in sea state 4 is well below half the response of the catamaran in heave:

7) It is possible to completely decouple catamaran pitch from cradle motion by reducing the four point suspension from the ship to a two point port and starboard arrangement.

8) By converting to a two point ship suspension, and moving the chain support point horizontally along LULU to the point of minimum heave, cradle heave would be reduced over present response.

In summary, as presently configured this system does not look any more attractive than the present surface recovery mode. 
A simple full scale calm water experimental measurement of the trail angle of the cradle suspended at 100 feet at a given speed would provide a point of calibration for model tests. If the trail angle is greater in real life than as modeled, the drag of the model is proportionally less, and the response of the cradle in full scale can be expected to be less than was observed in this study. Conversely, a smaller angle would suggest greater model drag than full scale, and hence greater full scale response due to the reduced viscous damping.

Experiments should be carried out in the tow tank using programmed sea spectra to duplicate real life random seas. Additionally, a $1 / 40$ scale model of ALVIN should be introduced in the vicinity of the lowered cradle to study any interface effects. Once this has been accomplished, dynamics of the cradle/ALVIN recovery as the chain is reeled in through the air-sea interface should be investigated.

Although the two point spring suspension using added mass effects appears quite feasible, more model tests are required. Cradle models of various size, buoyancy, and shape must be tested, as well as a much wider range of spring constants and possibly other devices and configurations. 


\section{BIBLIOGRAPHY}

Abkowitz, Martin A. Stability and Motion Control of Ocean Vehicles: Cambridge, Mass.: The M.I.T. Press, 1969.

Aldrich, Thomas B. "Submarine Hoist System." The Summary of Investigations Conducted in 1970. Unpublished Reference: Woods Hole, Mass.: Woods Hole Oceanographic Institution, 1971.

Booth, Ronald J.A. Comparative Study of the Heave and Pitch Motions of the Deep Submersible; ALVIN and her-Support Catamaran During Surface Operations: Unpublished Technical Memorandum No. DS-24. Woods Hole, Mass. : Woods Hole Oceanographic Institution, 1967.

Comstock, John P.(ed.). Principles of Naval Architecture. New York: SNAME, 1968 .

D'Areangelo, Amelio M. (ed.). Ship Design and Construction.: New York: SNAME, 1969.

Den Hartog, J.P. Mechanical Vibrations: 4th Edition, New York: McGraw-Hill Book Company, Inc., 1956.

Heller, S.R., and Motherway, D.L. "Comparative Heave Dynamics of Two Unusual Ship Configurations for Recovery of Submersibles." Nava1 Engineers Journa 1, (October, 1971); 28-36.

Hoerner, Sighard F. Fluid Dynamic Drag: Midland Park, N.J.: Published by author, 1965 .

James, R.W., Neumann, G., and Pierson, Jr.,. W.J. Practical Methods for Observing and Forecasting Ocean Waves by Means of Wave : Spectra and Statisties:-Washington:- U:S: Navy: Hydrographic Office, 1955 .

Kenny, James N. A Modeling System for the Bynamies of an Underwater Launch and Recovery of a:Deep-Submersible Unpublished Technical Memorandum No. 8-69. Woods Hole, Mass: Woods Hole Oceanographic Institution, 1969.

Korvin-Kroukovsky, V.B. Theory of Seakeeping. New York: SNAME, 1961.

Lowack, F.T. Lift Systems for Handling Heavy Objects rat Sea: Unpublished Engineers Thesis. Cambridge, Mass : : M.I.T., 1971

Mavor, J.M: Proposal for Program to Achieve Submerged Launch and Recovery of ALVIN with-LULU: Unpublished proposa1: Woods Hole, Mass.: Woods Hole Oceanographic Institution, 1971.

Moskowitz, L. "Estimates of the Power Spectra for Fully Developed 


$$
-47-
$$

Seas for Wind Speeds of 20 to 40 Knots". Technical Report for U.S. Naval Oceanographic Office, New York University, Research Division, 1963.

Newman, J.N. Marine Hydrodynamics. Unpublished lecture notes. Cambridge, Mass.: M.I.T., 1971.

Southerland, Arthur. "Mechanical Systems for Ocean Engineering." Naval Ship Systems Command-Teehnical News; (Mareh; 1972),

Vandiver, John K. Dynamic Analysis of a Launch and Recovery System for a Deep Submersible: Unpublished Mansucript . Reference No. 69-88. Woods Hole; Mass.: Woods Hole Oceanographic Institution, 1969 .

Wiege1, Robert L. Oceanographical Engineering. Prentice Ha11, 1964. 
$-48-$

APPENDIX

A. Data used in model radius of gyration calculations

B. Data/graphical presentation 
APPENDIX A

Data Used in Model Radius of Cyration Calculations

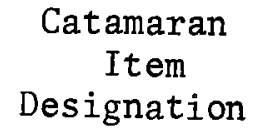

Tank 2S

Tank 3S (FWD)

FWD Arch

FWD Engine

FWD Hulls

FWD Deck

Tank 3S (aft.)

Tank 4S

Tank 5S

Tank 4P

Tank 5P

Aft. Arch

Deckhouse

Aft. Hu11s

Aft. Engine (2)

Fuel Aft. Arch

Misc. Aft.
Weight (Long Tons)

2.98

5.16

15

7.5

2.1 tons $/$ ft.

1.36 tons/ft.

4.14

9.3

11.2

7.73

9.2

17

5

2.1 tons/ft.

15

16.9

1.05 tons/ft.

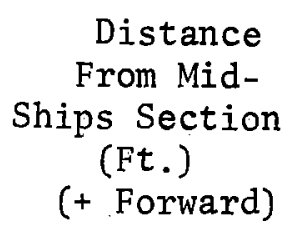

$+27$

$+5$

$+33$

$+33$

$+0-47.75$

$+11-47.75$

3.75

$-15$

$-31$

$-15$

$-15$

$-33$

$-33$

$-0-47.75$

$-45$

$-33$

$-0-47.75$ 
APPENDIX B

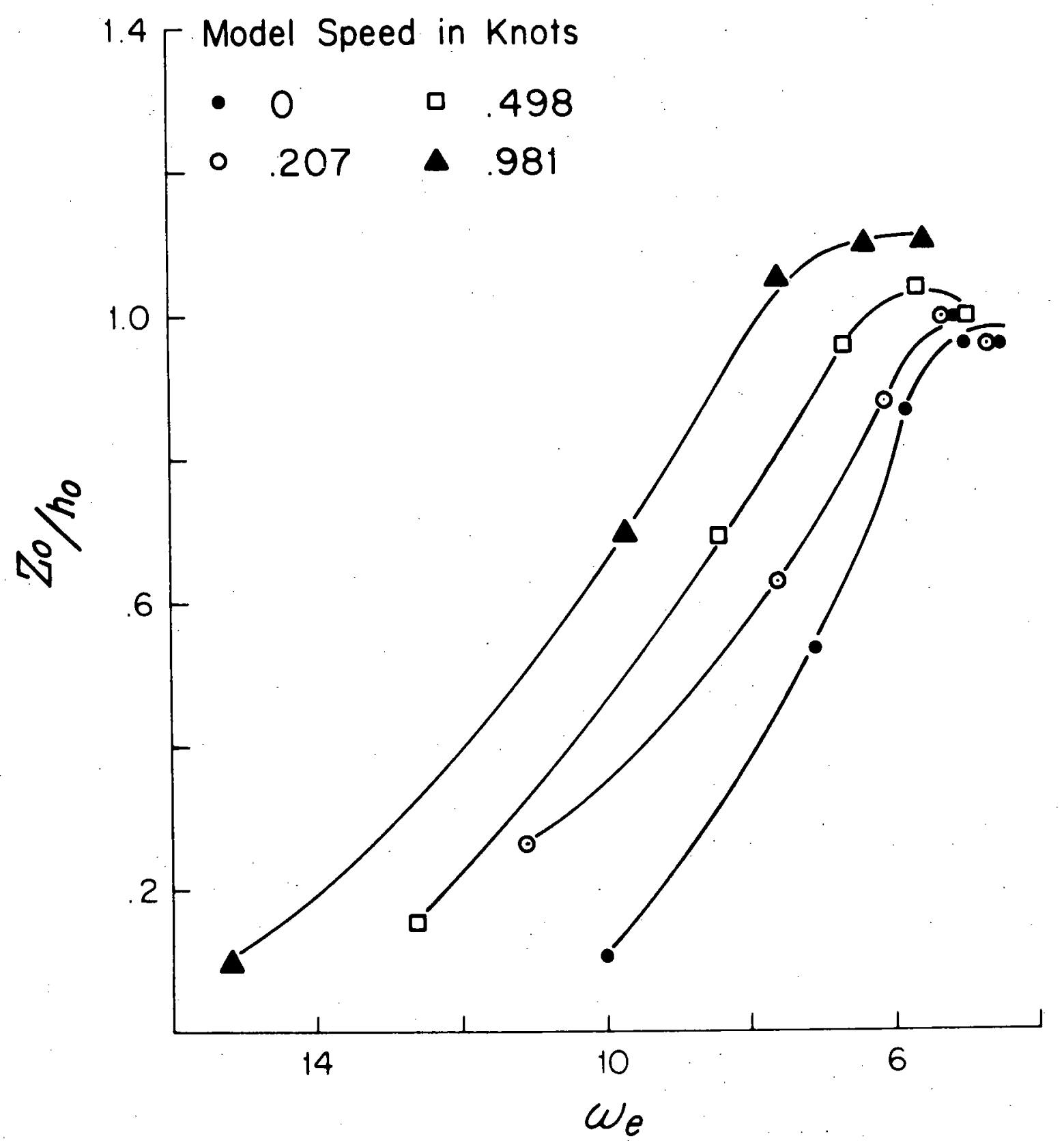

Figure B1. Catamaran Heave Response $\left(h_{0}=1^{\prime \prime}\right)$. 


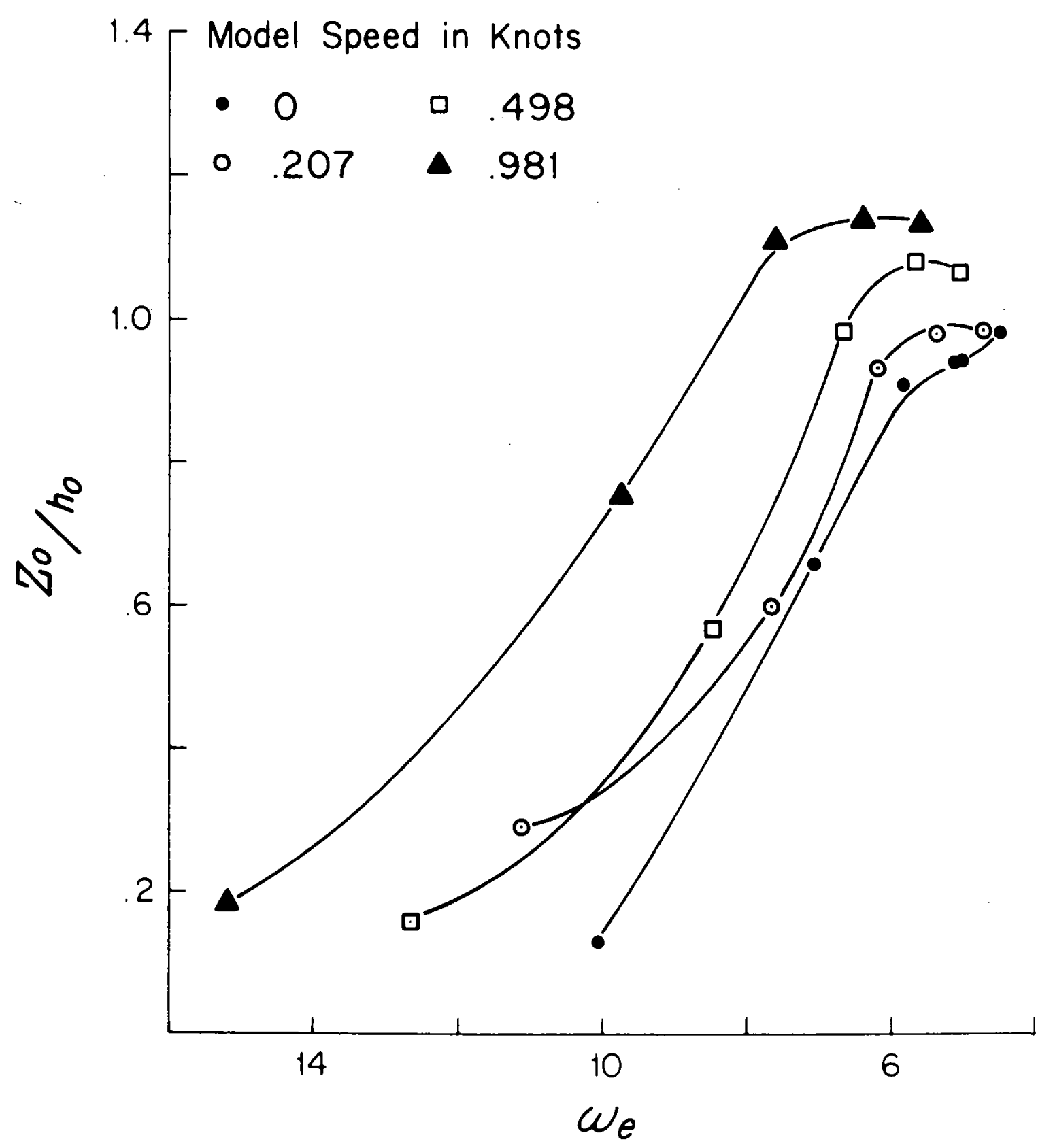

Figure B2. Catamaran Heave Response $\left(h_{0}=2.5^{\prime \prime}\right)$. 


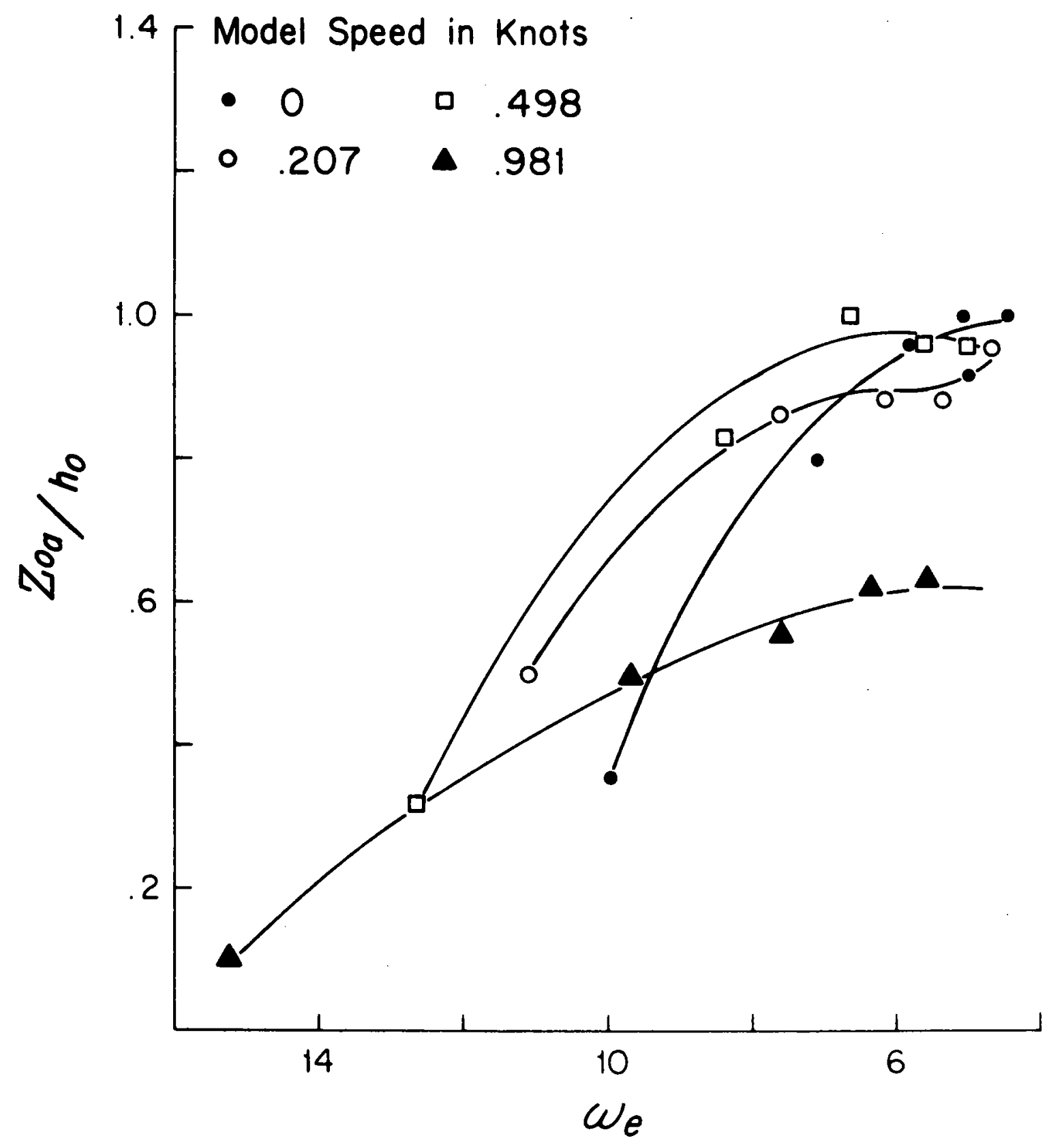

Figure B3. Cradle Heave Response $\left(h_{0}=1^{\prime \prime}\right)$. 


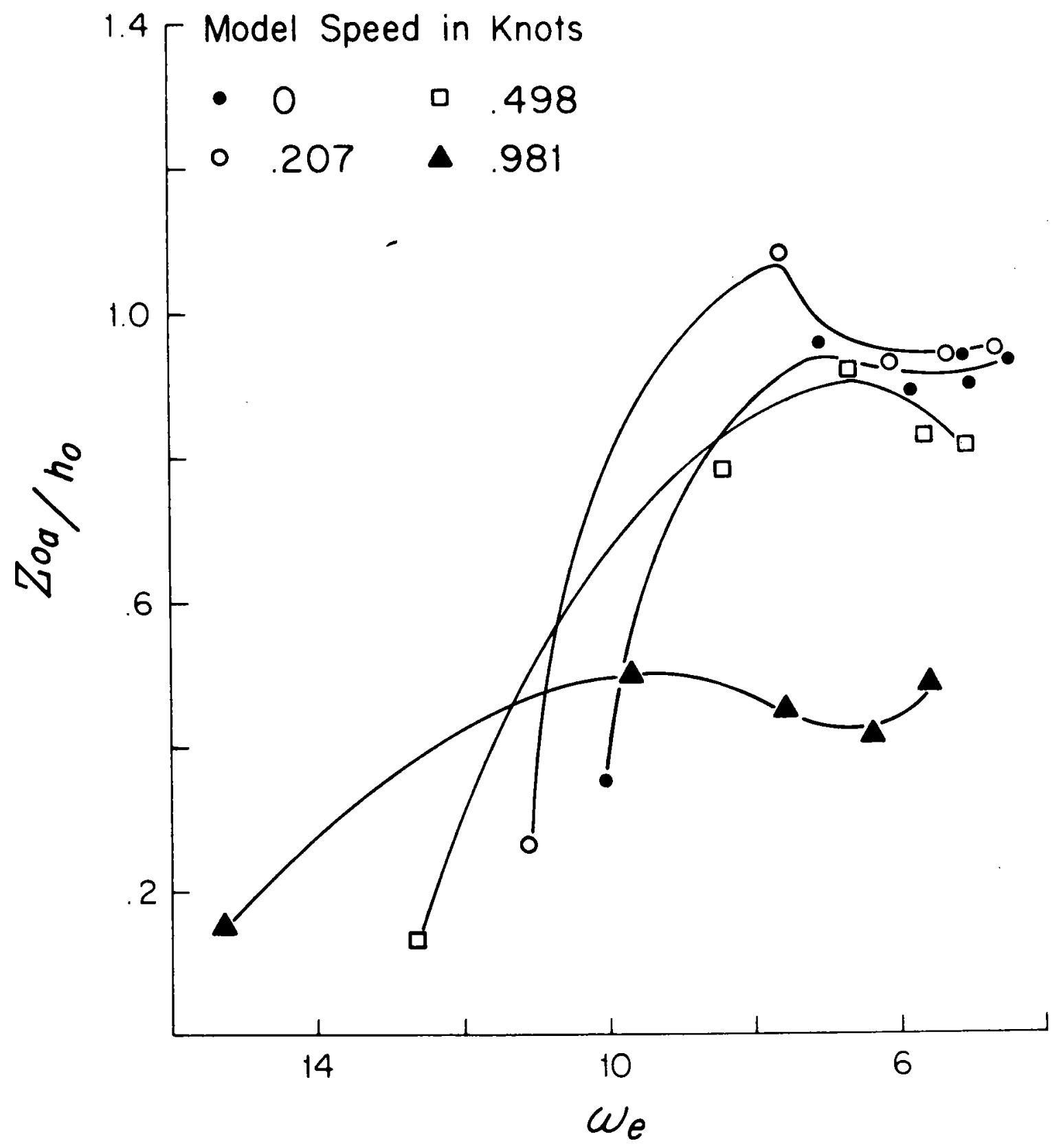

Figure B4. Cradle Heave Response $\left(h_{0}=2.5^{\prime \prime}\right)$. 


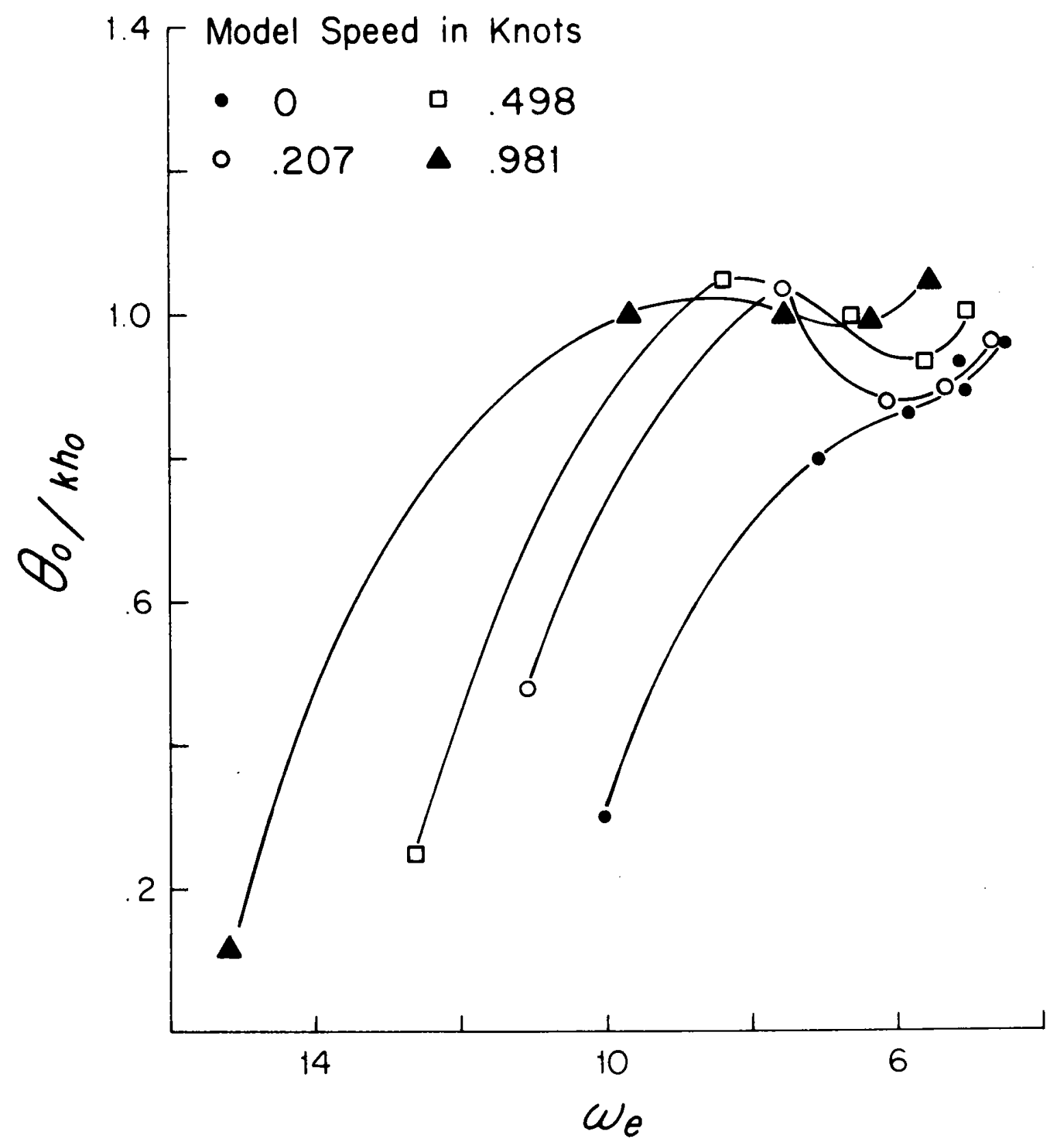

Figure B5. Catamaran Pitch Response $\left(h_{0}=1^{\prime \prime}\right)$. 


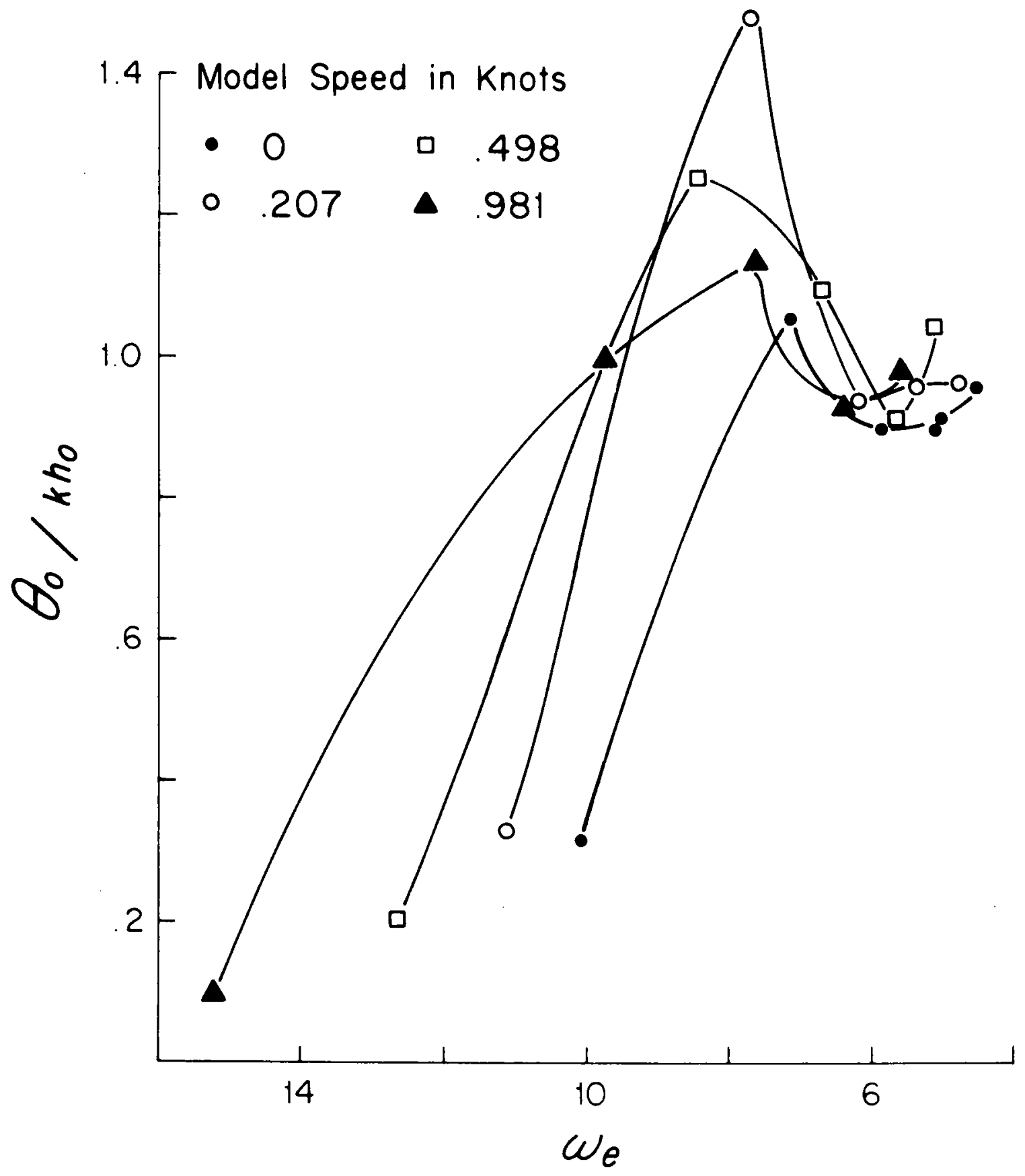

Figure B6. Catamaran Pitch Response $\left(h_{0}=2.5^{\prime \prime}\right)$. 


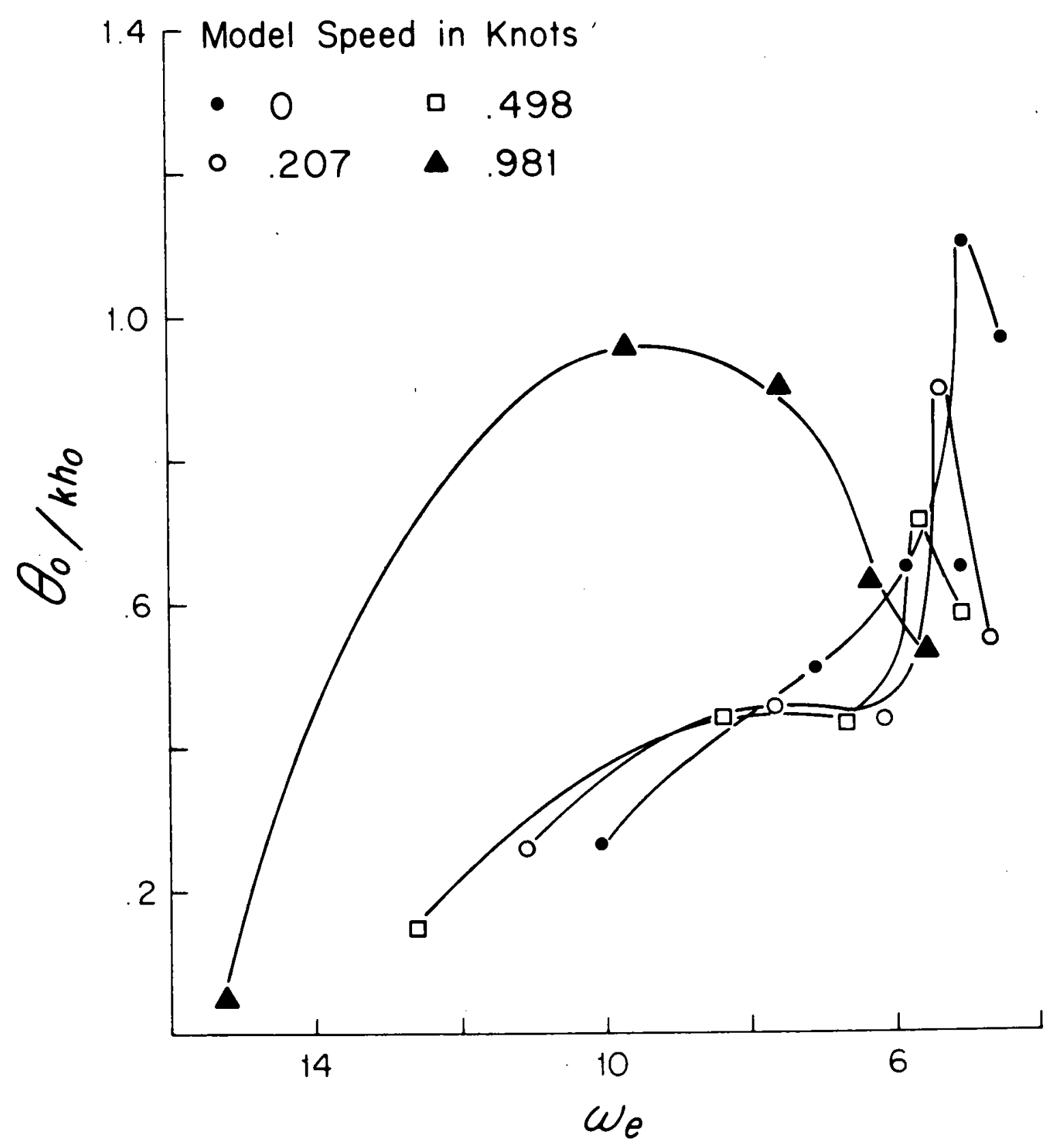

Figure B7. Cradle Pitch Response $\left(h_{0}=1^{\prime \prime}\right)$. 


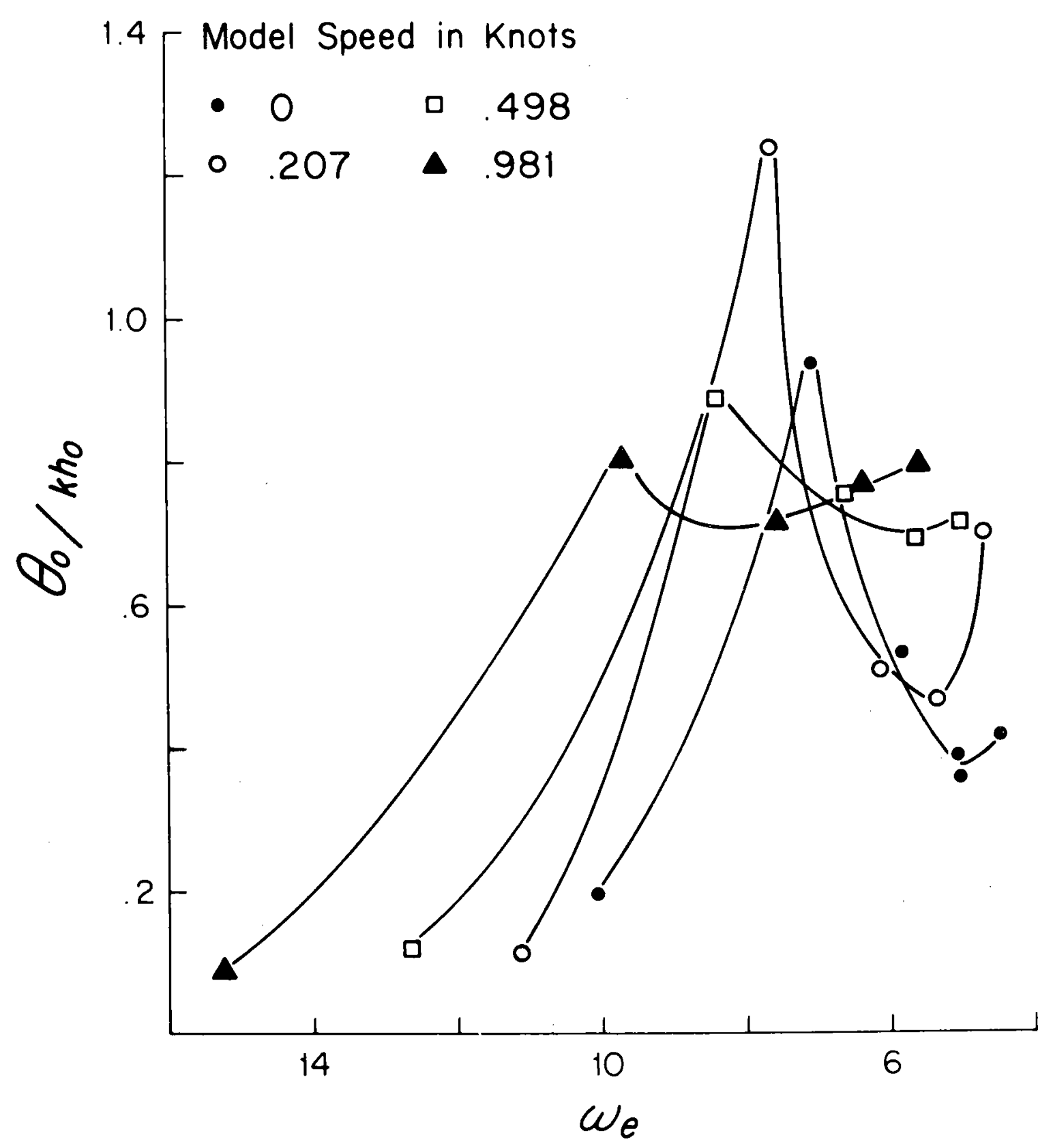

Figure B8. Cradle Pitch Response $\left(h_{0}=2.5^{\prime \prime}\right)$. 


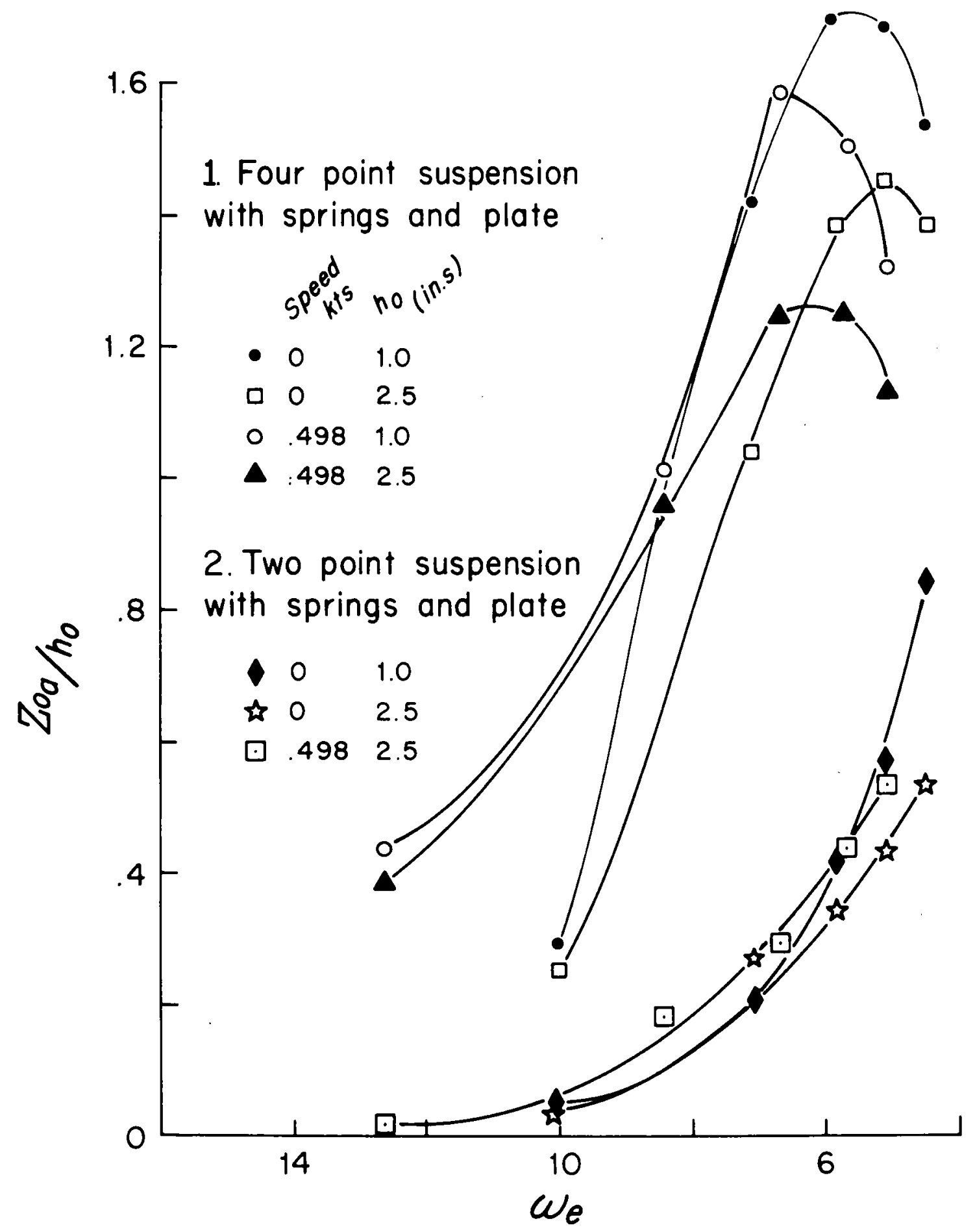

Figure B9. Modified Cradle Heave Response. 


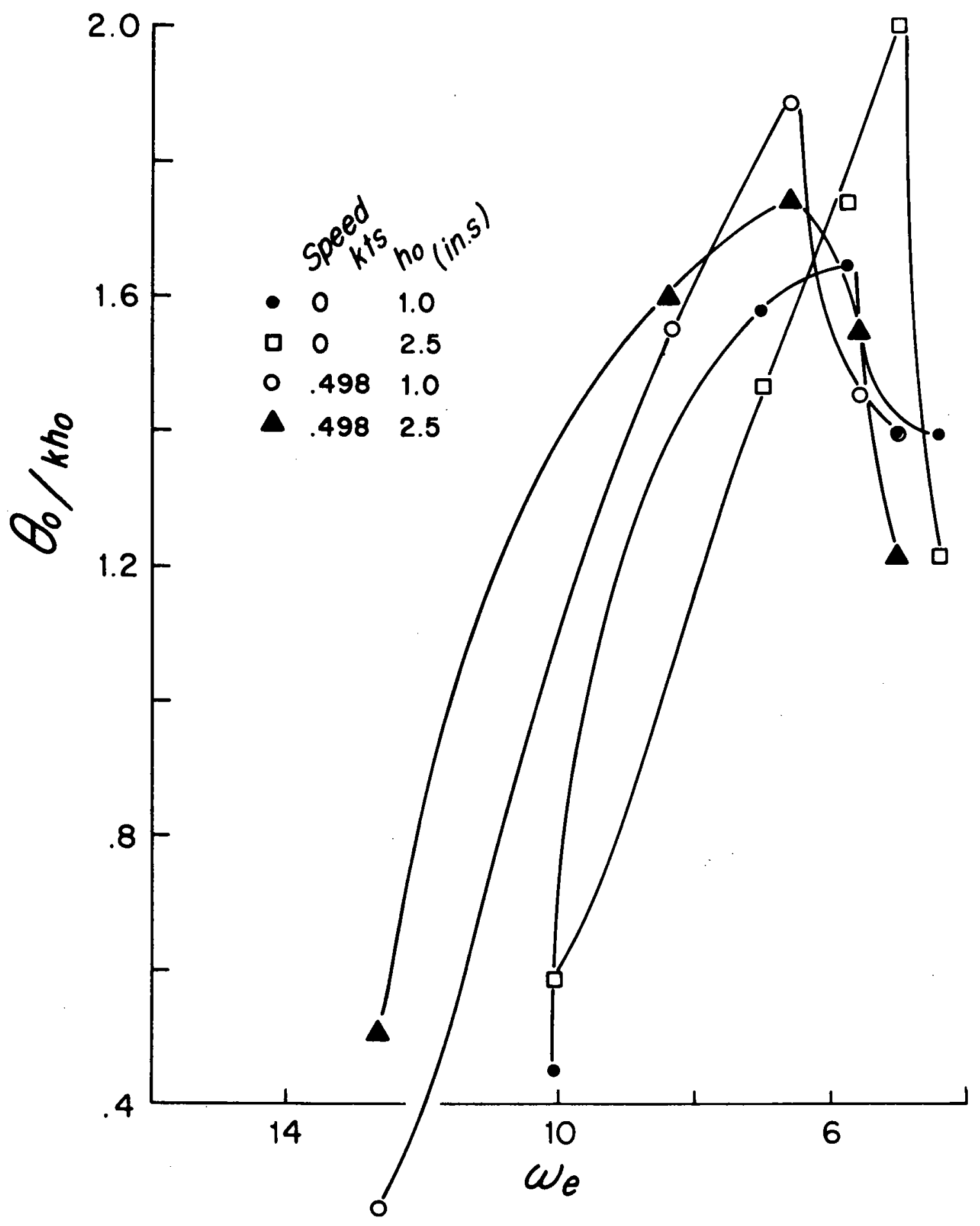

Figure B10. Modified Cradle Pitch Response. 


\begin{tabular}{|c|c|c|c|c|c|c|c|c|c|c|c|c|c|c|}
\hline \multirow[b]{2}{*}{$\begin{array}{l}\text { RUN } \\
\text { No. }\end{array}$} & $\begin{array}{ll}1 & M \\
2 & L \\
3 & T \\
4 & K\end{array}$ & \multicolumn{3}{|c|}{$\begin{array}{l}\text { Measured at Midships } \\
\text { Leading Edge } \\
\text { Trailing Edge } \\
K=\frac{2 \pi}{\lambda}\end{array}$} & \multicolumn{4}{|c|}{ CATAMARAN } & \multirow[b]{2}{*}{$\begin{array}{l}z_{o_{f}}^{2} \\
(\text { in) }\end{array}$} & \multirow[b]{2}{*}{$\begin{array}{c}z_{\mathrm{o}_{2}}^{3} \\
\text { (in) }\end{array}$} & \multicolumn{2}{|c|}{ CRADLE } & \multirow[b]{2}{*}{$\begin{array}{c}\theta \\
\text { (deg) }\end{array}$} & \multirow[b]{2}{*}{$\theta^{4} / \mathrm{Kh}_{0}$} \\
\hline & $\begin{array}{l}\lambda \\
(\mathfrak{f} \mathfrak{t})\end{array}$ & $\begin{array}{c}h_{0} \\
\text { (in) }\end{array}$ & $\underset{\substack{\left.u_{m} \\
\text { kts }\right)}}{ }$ & $\begin{array}{c}\omega_{e} \\
(\mathrm{rad} / \mathrm{sec})\end{array}$ & $\begin{array}{c}z_{0}^{1} \\
\text { (in) }\end{array}$ & $z_{0} / h_{0}$ & $\begin{array}{c}\theta \\
\text { (deg) }\end{array}$ & $\theta^{4} / \mathrm{Kh}_{0}$ & & & $z_{o_{f}} / h_{0}$ & $z_{o_{a} / h_{0}}$ & & \\
\hline 1 & 2 & 1.1 & 0 & 10.04 & .12 & .11 & 5.0 & .30 & .1 & .4 & .09 & .36 & 4.5 & .27 \\
\hline 2 & 4 & 1.25 & 0 & 7.10 & .66 & .53 & 7.5 & .80 & .65 & 1.0 & .52 & .80 & 4.75 & .51 \\
\hline 3 & 6 & 1.15 & 0 & 5.80 & 1.00 & .87 & 5.0 & .87 & 1.0 & 1.1 & .87 & .96 & 3.75 & .65 \\
\hline 4 & 7.75 & 1.1 & 0 & 5.10 & 1.10 & 1.00 & 4.0 & .94 & 1.0 & 1,1 & .91 & 1.0 & 2.75 & .65 \\
\hline 5 & 8 & 1.2 & 0 & 5.02 & 1.15 & .96 & 4.0 & .89 & 1.0 & 1.1 & .83 & .92 & 5.0 & 1.11 \\
\hline 6 & 10 & 1.2 & 0 & 4.49 & 1.15 & .96 & 3.5 & .97 & 1.05 & 1.2 & .88 & 1.0 & 3.5 & .97 \\
\hline 7 & 2 & 1.1 & .207 & 11.13 & .30 & .27 & 8.0 & .48 & .55 & .55 & .50 & .5 & 4.25 & .26 \\
\hline 8 & 4 & 1.15 & .207 & 7.64 & .72 & .63 & 9.0 & 1.04 & .55 & 1.0 & .49 & .87 & 4.0 & .46 \\
\hline 9 & 6 & 1.25 & .207 & 6.16 & 1.10 & .88 & 5.5 & .88 & .85 & 1.1 & .68 & .88 & 2.75 & .44 \\
\hline 10 & 8 & 1.25 & .207 & 5.29 & 1.25 & 1.00 & 4.25 & .90 & 1.0 & 1.1 & .80 & .88 & 4.25 & .90 \\
\hline 11 & 10 & 1.2 & .207 & 4.71 & 1.15 & .96 & 3.5 & .97 & 1.1 & 1.15 & .92 & .96 & 2.0 & .55 \\
\hline 12 & 2 & 1.25 & .498 & 12.68 & .2 & .16 & 4.75 & .25 & .2 & .4 & .16 & .32 & 2.75 & .15 \\
\hline 13 & 4 & 1.2 & .498 & 8.42 & .84 & .70 & 9.5 & 1.05 & .65 & 1.0 & .54 & .83 & 4.0 & .44 \\
\hline 14 & 6 & 1.15 & .498 & 6.68 & 1.1 & .96 & 5.75 & 1.00 & .85 & 1.15 & .74 & 1.0 & 2.5 & .43 \\
\hline 25 & 8 & 1.2 & .498 & 5.68 & 1.25 & 1.04 & 4.25 & .94 & 1.05 & 1.15 . & .88 & .96 & 3.25 & .72 \\
\hline 16 & 10 & 1.15 & .498 & 5.02 & 1.15 & 1.0 & 3.5 & 1.01 & .9 & 1.1 & .78 & .96 & 2.0 & .58 \\
\hline 17 & 2 & 1.55 & 0 & 10.04 & .2 & .13 & 7.5 & .32 & .1 & .55 & .06 & .35 & 4.5 & .19 \\
\hline 18 & 4 & 2.75 & 0 & 7.10 & 1.8 & .66 & 22.0 & 1.06 & 1.6 & 2.66 & .58 & .96 & 19.25 & .93 \\
\hline 19 & 6 & 2.65 & 0 & 5.80 & 2.4 & .91 & 12.0 & .90 & 2.1 & 2.35 & .79 & .89 & 7.0 & .53 \\
\hline 20 & 7.75 & 2.65 & 0 & 5.10 & 2.5 & .94 & 9.25 & .90 & 2.3 & 2.5 & .87 & .94 & 4.0 & .39 \\
\hline 21 & 8 & 2.6 & 0 & 5.02 & 2.45 & .94 & 9.0 & .92 & 2.2 & 2.35 & .85 & .90 & 3.5 & .36 \\
\hline 22 & 10 & 2.75 & 0 & 4.49 & 2.7 & .98 & 8.0 & .97 & 2.45 & 2.55 & .89 & .93 & 3.5 & .42 \\
\hline 23 & 2 & 1.7 & .207 & 11.13 & .5 & .29 & 8.5 & .33 & .4 & .45 & .24 & .27 & 2.75 & .11 \\
\hline 24 & 4 & 2.6 & .207 & 7.64 & 1.55 & .60 & 29.0 & 1.48 & 1.3 & 2.8 & .50 & 1.08 & 24.0 & 1.23 \\
\hline
\end{tabular}


Summary of Data

\begin{tabular}{|c|c|c|c|c|c|c|c|c|c|c|c|c|c|c|}
\hline \multirow[b]{2}{*}{$\begin{array}{l}\text { RUN } \\
\text { No. }\end{array}$} & \multicolumn{4}{|c|}{$\begin{array}{ll}1 & \text { Measured at Midships } \\
2 & \text { leading Edge } \\
3 & \text { Trailing Edge } \\
4 & K=\frac{2 \pi}{\lambda}\end{array}$} & \multicolumn{4}{|c|}{ CATAMARAN } & \multicolumn{6}{|c|}{ CRADLE } \\
\hline & $\stackrel{\lambda}{(f t)}$ & $\begin{array}{c}h_{o} \\
\text { (in) }\end{array}$ & $\underbrace{u_{m}}_{(\mathrm{kts})}$ & $\begin{array}{c}\omega_{\mathrm{e}} \\
(\mathrm{rad} / \mathrm{sec})\end{array}$ & $\begin{array}{c}z_{\mathbf{o}}^{1} \\
\text { (in) }\end{array}$ & $z_{0} / h_{0}$ & $\begin{array}{c}\theta \\
(\operatorname{deg})\end{array}$ & $\theta^{4} / \mathrm{Kh}_{0}$ & $\underset{\text { (inf }}{\mathrm{z}_{\mathrm{o}}^{2}}$ & $\begin{array}{c}z_{\mathrm{o}}^{3} \\
(\mathrm{in})\end{array}$ & $\mathrm{z}_{\mathrm{of} / \mathrm{h}_{\mathrm{o}}}$ & $\mathrm{z}_{\mathbf{a}_{\mathrm{a} / \mathrm{h}_{\mathrm{o}}}}$ & $\begin{array}{c}\theta \\
\text { (deg) }\end{array}$ & ${ }^{04}{ }_{\mathrm{Kh}_{\mathrm{O}}}$ \\
\hline 25 & 6 & 2.65 & .207 & 6.16 & 2.45 & .93 & 12.5 & .94 & 2.05 & 2.45 & .78 & .93 & 6.75 & .51 \\
\hline 26 & 8 & 2.55 & .207 & 5.29 & 2.5 & .98 & 9.25 & .97 & 2.2 & 2.4 & .86 & .94 & 4.5 & .47 \\
\hline 27 & 20 & 2.75 & .207 & 4.71 & 2.7 & .98 & 8.0 & .97 & 2.45 & 2.6 & .89 & .95 & 5.75 & .70 \\
\hline 28 & 2 & 1.5 & .498 & 12.68 & .24 & .16 & 4.75 & .21 & .2 & .2 & .13 & .13 & 2.75 & .12 \\
\hline 29 & 4 & 2.7 & .498 & 8.42 & 1.55 & .57 & 25.5 & 1.26 & 1.25 & 2.1 & .46 & .78 & 18.0 & .89 \\
\hline 30 & 6 & 2.55 & .498 & 6.68 & 2.5 & .98 & 14.0 & 1.10 & 1.85 & 2.35 & .73 & .92 & 9.75 & .76 \\
\hline 31 & B & 2.6 & .498 & 5.68 & 2.8 & 1.08 & 9.0 & .92 & 1.85 & 2.15 & .71 & .83 & 6.75 & .69 \\
\hline 32 & 10 & 2.7 & .498 & 5.02 & 2.9 & 1.07 & 8.5 & 1.05 & 2.05 & 2.2 & .76 & .82 & 5.75 & .71 \\
\hline 33 & 7.85 & 1.2 & .207 & 5.35 & 1.15 & .96 & 4.25 & .93 & .95 & 1.05 & .79 & .88 & 3. 25 & .71 \\
\hline 34 & 9.69 & 1.15 & .498 & 5.12 & 1.2 & 1.04 & 3.5 & .98 & .95 & 1.1 & .83 & .96 & 3.5 & .98 \\
\hline 35 & 7.85 & 2.6 & .207 & 5.35 & 2.5 & .96 & 9.25 & .93 & 2.1 & 2.35 & .81 & .91 & 5.5 & .55 \\
\hline 36 & 9.69 & 2.75 & .498 & 5.12 & 2.9 & 1.05 & 9.0 & 1.06 & 2.15 & 2.5 & .78 & .91 & 6.25 & .73 \\
\hline 37 & 2 & 1.0 & .981 & 15.24 & .1 & .1 & 1.75 & .12 & .15 & .1 & .15 & .1 & .75 & .05 \\
\hline 38 & 4 & 1.0 & .981 & 9.70 & .7 & .7 & 7.5 & 1.00 & .85 & .5 & .85 & .5 & 7.25 & .96 \\
\hline 39 & 6 & 1.0 & .981 & 7.53 & 1.05 & 1.05 & 5.0 & 1.00 & .35 & .55 & .35 & .55 & 4.5 & .90 \\
\hline 40 & 8 & 1.05 & .981 & 6.32 & 1.15 & 1.10 & 3.75 & .95 & .4 & .65 & .38 & .62 & 2.5 & .63 \\
\hline 41 & 10 & .95 & .981 & 5.53 & 1.05 & 1.11 & 3.0 & 1.05 & .45 & .6 & .47 & .63 & 1.5 & .53 \\
\hline 42 & 2 & 1.3 & .981 & 15.24 & .23 & .18 & 2.0 & .10 & .2 & .2 & .15 & .15 & 1.75 & .09 \\
\hline 43 & 4 & 2.0 & .981 & 9.70 & 1.5 & .75 & 15.0 & 1.00 & .85 & 1.0 & .43 & .5 & 12.0 & .80 \\
\hline 44 & 6 & 2.1 & .981 & 7.53 & 2.3 & 1.11 & 12.0 & 1.14 & .9 & .95 & .43 & .45 & 7.5 & .71 \\
\hline 45 & 8 & 2.15 & .981 & 6,32 & 2.45 & 1.14 & 7.5 & .93 & .9 & 1.1 & .42 & .51 & 6.25 & .77 \\
\hline 46 & 10 & 2.2 & .981 & 5.53 & 2.5 & 1.14 & 6.5 & .98 & 1.05 & 1.4 & .48 & .64 & 5.25 & .79 \\
\hline 101 & 2 & 1.05 & 0 & 10.04 & .13 & .12 & 4. 25 & .27 & .5 & .3 & .48 & .29 & 7.25 & .46 \\
\hline 102 & 4 & .95 & 0 & 7.10 & .46 & .48 & 6.75 & .95 & .65 & 1.35 & .68 & 1.42 & 11.25 & 1.58 \\
\hline 103 & 6 & 1.0 & o & 5.80 & .9 & .9 & 4.75 & .95 & 1.3 & 1.7 & 1.3 & 1.7 & 8.25 & 1.65 \\
\hline 104 & 8 & .95 & $\mathbf{0}$ & 5.02 & 1.05 & 1.11 & 3.75 & 1.05 & 1.35 & 1.6 & 1.42 & 1.68 & 5.0 & 1.40 \\
\hline 105 & 10 & .95 & o & 4.49 & 1.1 & 1.16 & 3.0 & 1.05 & 1.5 & 1.45 & 1.37 & 1.53 & 4.0 & 1.40 \\
\hline 106 & 2 & 1.6 & 0 & 10.04 & .24 & .15 & 7.25 & .30 & .8 & .4 & .5 & .25 & 14.25 & .59 \\
\hline
\end{tabular}


Summary of Data

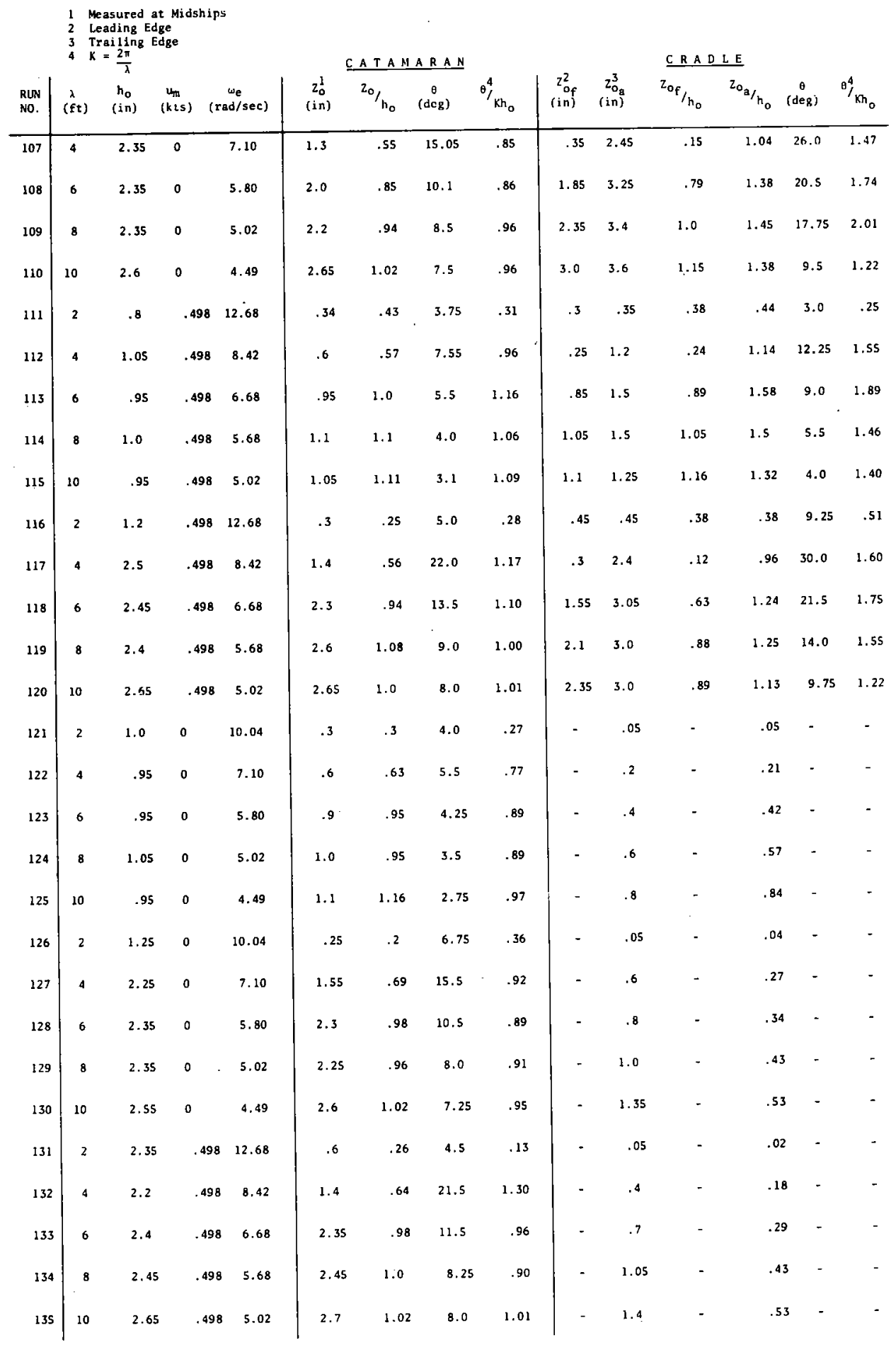


Office of Naval Research Department of the Navy

Attn: Code 466

$$
\text { 102-OS }
$$

Arlington, Virginia 22217

Director

Office of Naval Research

Branch Office

495 Summer Street

Boston, Massachusetts $02210 \quad 1$

Chief of Naval Operations

Department of the Navy

Attn: Op $03 \mathrm{u}$

71

95

Washington, D. C。 20350

Commander

Nava1 Ship Systems Command

Department of the Navy

Attn: SHIPS 03

$\begin{array}{ll}\text { OOV } 1 & 1 \\ 0342 & 1 \\ 205 & 1 \\ 00 \mathrm{C} & 1 \\ \text { PMS } 381 & 1\end{array}$

Washington, D。C. 20360

Commander

Naval Ship Research \& Development Center

Attn: Code 731

Washington, D. C。 20007

Environmental Science Department 1 U.S. Naval Academy

Annapolis, Maryland 21402

Director

Naval Research Laboratory

Attn: Code 2029 and 2040

Technical Information Division 6

Washington, D。 C. 20390

Commander

U.S. Nava1 Oceanographic Office

Washington, 'D。C. 20390

Attn: Code 037-B

1640
Commander

Naval Electronics Lab. Center

Attn: Code 2400

3119

4320

San Diego, California 92152

Naval Post Graduate School

Attn: Librarian

Dept。of Meteorology \& Oceanography

Monterey, Califonnia 93940

Commanding Officer \& Director Naval Underwater Systems Center New London Laboratory

New London, Connecticut 93940

Commander

Submarine Forces Atlantic Fleet Norfolk, Virginia 23511

Commander

Submarine Forces Pacific Fleet

Fleet Post Office

San Francisco, California 96601

Commander

Submarine Development Group ONE Fleet Post Office

San Francisco, California 96601

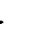

$$
\text { O-I-C. TURTLE }
$$

Commander

Submarine Development Group ONE

Fleet Station Post Office

San Diego, California 92132

Commander

Submarine Development Group TWO

Fleet Post Office

New York, New York 09501

$\mathrm{C} .0$ 。 NR-1

$\mathrm{C} .0$ 。DOLPHIN (AGSS555)

1

1

Defense Documentation Center

Cameron Station

Alexandria, Virginia 22314

Commanding officer

Naval Ship Research \& Development Laboratory

Annapolis, Maryland 21402 
Chesapeake Bay Institute

The John Hopkins University

Macaulay Hal1

Baltimore, Maryland 21218

Mr. Eugene C1ay

Hahn \& Clay Machine \& Boiler Works 5100 Clinton Drive

Houston. Texas 77020

Mr。 $H_{0}$ W Volberg

Straza Industries

790 Greenfield Drive

E1 Cajon, California 92021

Dr. Harold Edgerton

Edgerton, Germeshausen \& Grier

160 Brookline Avenue

Boston, Massachusetts 02215

Mr. Samue1 Raymond

Benthos Company

old Main Street

N. Falmouth, Massachusetts. 02556

Mr. George Hatchette

Oceanographic Engineering Corp.

P.0. Box 1560

La Jolla, Calffornia 92038

Mr. Herbert Fields

294 Washington Street

Boston, Massachusetts

Director

Narragansett Marine Laboratory University of Rhode Island

Kingston, Rhode Is land 02881

President ...

U.S. Naval War College

Newport, Rhode Island 02840

Daptain Ballinger, USN Retired

Sun Shipbuilding Corp.

Chester, Pennsylvania 19013

Lukens Stee1 Company

Coatesvil1e, Pennșylvania 19320

Mr. A. Tuthill

International Nicke1 Company

67 Wa11 Street

New York, New Ybrk 10005

1
Capt. C.B. Momsen, USN Retired

AC Electronics/Defense Research Lab.

6767 Hollister Avenue

Goleta, California . 93017

Westinghouse Electric Corp.

DEEPSTAR Project

Underseas Division

Washington Boulevard

2

Baltimore, Maryland 21230

Programmed \& Remote Systems Corp. 899 West Highway 96

St. Paul, Minnesota. $55112 \quad 1$

Mr。H。E。Froeh1ich

3016 Armour Terrace

Minneapolis, Minnesota 55418.1

Reynolds Submarine Service Corp.

615 South West Second Avenue

Miami, Florida 33130

Autonetics

Division of North America Aviation

Ocean Systems Operation

3370 Mira Loma Avenue

Aniaheim, California. 92085

Hawaii Technological Information Center P.0. Box 2359

Honolulu, Hawaii 92085

1

Lehigh University

Bethelehem, Pennsylvania 18015

Attn: Dr. Adrian F。 Richards

Oceanographer of the Navy

Code ON 41

$732 \mathrm{~N}$. Washington St.

Alexandria, Virginia 22314

2

J. Seward Johnson

501 George Street

New Brunswick, New Jersey 089031

Edwin Link

10 Avon Road

Binghamton, New York 13905 .

1

Taylor A。 Pryor

Makapuu Oceanic Center

Makapuu Point, Waimanalo

Hawai i 96795 
United States Coast Guard Academy

New London, Connecticut $06320 \quad 1$

University of Rhode Island

Ocean Engineering Department

College of Engineering

Kinston, Rhode Island .02881

International Hydrodynamics

145 Riverside Drive

N. Vancouver 2, B.C.

Office of the Commandant

United States Coast Guard Bldg. 1300 E. Street, N.W.

Washington, D. C. $20591 \quad 1$

United States Coast Guard Building

Office of Engineering

$\mathrm{Rm} 5202$

1300 E. Street, N.W.

Washington, D. C. $20591 \quad 1$

Commander

Portsmouth Naval Ship Yard

Portsmouth, New Hampshire

Supervisor of Shipbuilding

Conversion and Repair, USN

Groton, Connecticut 20360

Nava1 Ship Engineering Center

Center Building

Prince Georges Center

Hyattsvi1le, Maryland 20782 


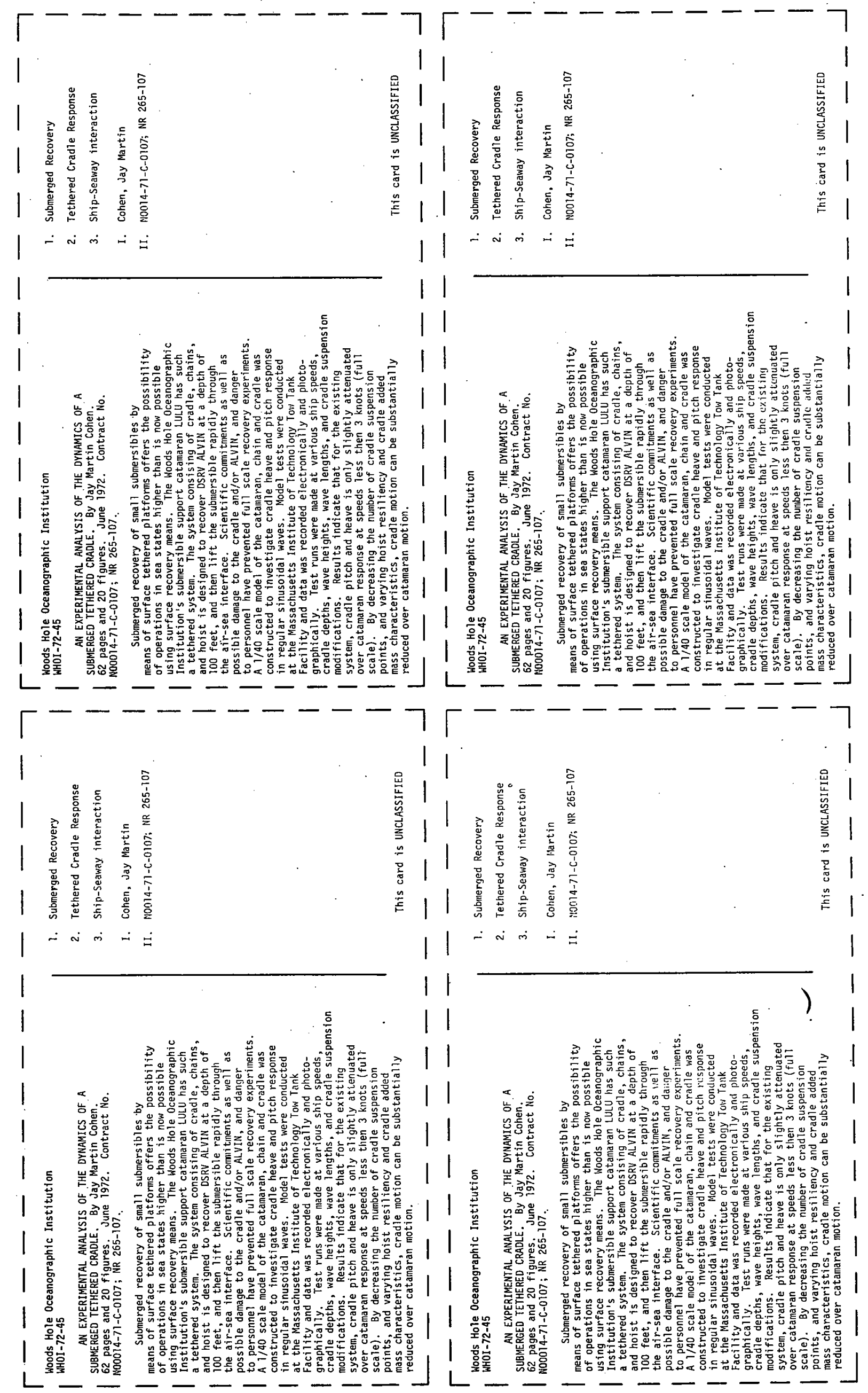




\section{DOCUMENT CONTROL DATA - R\&D}

(Security ciasaitication of title, bady of abstract and indexing annotation must he ontered when the averall report is classified) 1. ORIGINATIN G ACTIMITY (Corpor.gro author)

Woods Hole Oceanographic Institution

Woods Hole, Massachusetts 02543

2a. REPORT SECURITY CLASSIFICATION UNCLASSIFIED

2b. GROUP

3. REPORT TITLE

AN EXPERIMENTAL ANALYSIS OF THE DYNAMICS OF A SUBMERGED TETHERED CRADLE

4. DESCRIPTIVE NOTES (TYPo of repost and inclusive dates)

Technical Report

5. AUTHOR(S) (Last nama, firat name, initial)

Jay Martin Cohen

\begin{tabular}{|c|c|c|}
\hline $\begin{array}{l}\text { 6. REPORT DATE } \\
\text { June } 1972\end{array}$ & $\begin{array}{c}\text { 7A. TOTAL NO. OF PAGES } \\
62\end{array}$ & $\begin{array}{c}\text { 7b. NO. OF REFS } \\
18\end{array}$ \\
\hline $\begin{array}{l}\text { Ba. CONTRACT OR GRANT No. } \\
\text { NOO014-71-C-0107; NR 265-107 } \\
\text { b. PROJECT NO. }\end{array}$ & \multicolumn{2}{|c|}{$\begin{array}{l}\text { 9. ORIGINATOR'S REPORT NUMEER(S) } \\
\text { WHOI - } 72-45\end{array}$} \\
\hline c. & 9b. OTHER REPOAT NO(S) & other numbers that may be assigned \\
\hline
\end{tabular}

10. AVAIL ABILITY/LIMITATION NOTICES

Approved for public release, distribution untimited.

11. SUPPL. EMENTARY NOTES

12. SPONSORING MILITARY ACTIVITY
Office of Naval Research
Code 466
Arlington, Virginia 22217

13. AESTRACT

Submerged recovery of smal1 submersibles by means of surface tethered platforms offers the possibility of operations in sea states higher than is now possible using surface recovery means. The Woods Hole Oceanographic Institution's submersible support catamaran LULU has such a tethered system. The system consisting of cradle, chains, and hoist is designed to recover DSRV ALVIN at a depth of 100 feet, and then lift the submersible rapidly through the air-sea interface. Scientific commitments as well as possible damage to the cradle and/or ALVIN, and danger to personnel have prevented full scale recovery experiments. A 1/40 scale model of the catamaran, chain and cradle was constructed to investigate cradle heave and pitch response in regular sinusoidal waves. Model tests were conducted at the Massachusetts Institute of Technology Tow Tank Facility and data was recorded electronically and photographically. Test runs were made at various ship speeds, cradle depths, wave heights, wave lengths, and cradle suspension modifications. Results indicate that for the existing system, cradle pitch and heave is only slightly attenuated over catamaran response at speeds less then 3 knots (full scale). By decreasing the number of cradle suspension points and varying hoist resiliency and cradle added mass characteristics, cradle motion can be substantially reduced over catamaran motion. 
Unclassified

Security Classification

\begin{tabular}{|ll}
\hline 14. & KEY wORDS \\
\hline 1. & Submerged Recovery \\
2. & Tethered Cradle Response \\
3. & Ship-Seaway interaction
\end{tabular}

\section{INSTRUCTIONS}

1. ORIGINATING ACTIVITY: Enter the name and address of the contractor, subcontractor, grantee, Department of Defense activity or other organization (corporate author) issuing the report.

2a. REPORT SECURTY CLASSIFICATION: Enter the overall security classification of the report. Indicate whether "Restricted Data" is included Marking is to be in accordance with appropriate security regulations.

2b. GROUP: Automatic downgrading is specified in DoD Directive 5200.10 and Armed Forces Industrial Manual. Enter the group number. Also, when applicable, show that optional markings have been used for Group 3 and Group 4 as authorized.

3. REPORT TITLE: Enter the complete report title in all capital lettera. Titles in all cases should be unclassifled. If a meaningful title cannot be selected without classification, show title classification in all capitals in parenthesis immediately following the title.

4. DESCRIPTIVE NOTES: If appropriate, enter the type of report, e.g., interim, progress, summary, annual, or final. Give the inclusive dates when a specific reporting period is covered.

5. AUTH\$R(S): Erter the name(s) of author(8) as shown on or In the teport. Enter last name, firot name, middle initial. If military, ahow rank and branch of service. The name of the princlpal author is an ahsolute minimum requirement.

6. REPORT DATE: Enter the date of the report as day, month, year; or month, year. If more than one date appears on the report, use date of publication.

7a. TOTAL NUMBER OF PAQE:9; The total page count should follow normal pagination procedures, 1 , $\theta_{1}$, enter the number of pages containing information

7b. NUMBER OF REFERENCES Enter the total number of references cited in the report.

8a. CONTRACT OR ORANT NUMBERI If appropriate, onter the applicable number of the oontraet or grant under which the report was written.

8b, 8c, 8d. 8ROJECT NUMBERt Enter the approprlate military department identificatlon, weh ae projoct number, subproject number, system numbers, task number, etc.

9a. ORIGINATOR'S REPORT NUMBER(s): Enter the off. cial report number by which the document will be identified and controlled by the originating activity. This number must be unique to this report.

9b. OTHER REPORT NUMBER(S): If the report has been assigned any other report numbers (either by the orlalinator or by the sponsor), also enter this number(s).

10. AVAILABILITY/LIMTATION NOTICES: Enter any $11 \mathrm{~m}$ itations on further dissemination of the report, other than those imposed by security classification, using standard statements such as:

(1) "Qualified requesters may obtain copies of this report from DDC"

(2) "Foreign announcement and dissemination of this report by DDC is not authorized."

(3) "U. S. Government agencies may obtain copies of this report direatly from DDC. Other qualified DDC users shall request through

(4) "U. S. military agencies may obtain copies of this report directly from DDC. Other qualified users shall request through ."

(5) "All distribution of this report is controlled Qualified DDC users shall request through ."

If the report has been furnished to the Office of Technical Services, Department of Commerce, for sale to the public, indicate this fact and enter the price, if known

11. SUPPLEMENTARY NOTES: Use for additional explanatory notes.

12. SPONSORING MILITARY ACTIVITY: Enter the name of the departmental project office or laboratory sponsoring (payIn $f \circ r$ ) the research and development. Include address.

13. ABSTRACT: Enter an abstract giving a brief and factual summary of the document indicative of the report, even though it may also appear elsewhere in the body of the technical report. If edditional space is required, continuation sheet shall be attached.

It is highly desirable that the abstract of classified reports be unclassifiod. Each paragraph of the abstrect shall end with an indication of the military socurity clasolflcation of the information in the paragraph, represented as (TS), (S), (C), or (U)

There is no limitation on the length of the abstract. However, the suggested length is from 150 to 225 words.

14. KEY WORDS: Key words are technically meaningful terms or short phrases that characterice a report and may be used as Index entrles for cotaloging the report. Key words must be selected so that no security classification is required. Identiflers, such as equipment model designation, trade name; military project code name, geographic location, may be used as key words but will be followed by an indication of technical context. The assignment of links, rales, and weights is optional. 